\title{
Changes in Circulating Stem and Progenitor Cell Numbers Following Acute Exercise in Healthy Human Subjects: a Systematic Review and Meta-analysis
}

\author{
M. Schmid ${ }^{1}$ (D) · J. M. Kröpfl ${ }^{1}$ C. M. Spengler ${ }^{1,2}$ \\ Accepted: 1 December 2020 / Published online: 2 January 2021 \\ (C) The Author(s) 2021, corrected publication 2021
}

\begin{abstract}
Despite of the increasing number of investigations on the effects of acute exercise on circulating stem and progenitor cell (SC) numbers, and in particular on respective subgroups, i.e. endothelial (ESC), hematopoietic (HSC), and mesenchymal (MSC) stem and progenitor cells, a consensus regarding mechanisms and extent of these effects is still missing. The aim of this meta-analysis was to systematically evaluate the overall-effects of acute exercise on the different SC-subgroups and investigate possible subject- and intervention-dependent factors affecting the extent of SC-mobilization in healthy humans. Trials assessing SC numbers before and at least one timepoint after acute exercise, were identified in a systematic computerized search. Compared to baseline, numbers were significantly increased for early and non-specified SCs (enSCs) until up to $0.5 \mathrm{~h}$ after exercise (05 min: +0.64 [Standardized difference in means], $p<0.001 ; 6-20 \mathrm{~min}:+0.42, p<0.001 ; 0.5$ h: $+0.29, p=0.049)$, for ESCs until 12-48 h after exercise (0-5 min: $+0.66, p<0.001 ; 6-20 \mathrm{~min}:+0.43 p<0.001 ; 0.5 \mathrm{~h}:+0.43, p=0.002 ; 1 \mathrm{~h}:+0.58, p=0.001 ; 2 \mathrm{~h}$ : $+0.50, p=0.002 ; 3-8 \mathrm{~h}:+0.70, p<0.001 ; 12-48 \mathrm{~h}:+0.38, p=0.003)$ and for HSCs at $0-5 \min (+0.47, p<0.001)$ and at $3 \mathrm{~h}$ after exercise $(+0.68, p<0.001)$. Sex, intensity and duration of the intervention had generally no influence. The extent and kinetics of the exercise-induced mobilization of SCs differ between SC-subpopulations. However, also definitions of SC-subpopulations are non-uniform. Therefore, finding a consensus with a clear definition of cell surface markers defining ESCs, HSCs and MSCs is a first prerequisite for understanding this important topic.
\end{abstract}

Keywords Stem and progenitor cells $\cdot$ Acute exercise $\cdot$ Meta-analysis $\cdot$ Systematic review $\cdot$ Stem cell mobilization $\cdot$ Endothelial $\cdot$ Hematopoietic $\cdot$ Mesenchymal $\cdot$ Kinetics $\cdot$ Moderator variables

\section{Introduction}

Stem cells (SCs) have the potential to self-renew and differentiate into cell types of specific tissues or organs, allowing

J. M. Kröpfl and C. M. Spengler contributed equally to this work.

C. M. Spengler

christina.spengler@hest.ethz.ch

M. Schmid

michelle.schmid@hest.ethz.ch

J. M. Kröpfl

julia.kroepfl@hest.ethz.ch

1 Exercise Physiology Lab, Institute of Human Movement Sciences and Sport ETH Zurich, Winterthurerstrasse 190, CH-8057 Zurich, Switzerland

2 Zurich Center for Integrative Human Physiology (ZIHP), University of Zurich, Winterthurerstrasse 190, CH-8057 Zurich, Switzerland for cell replacement and turnover. In adults, different groups of stem and progenitor cells, e.g. hematopoietic (HSCs), endothelial (ESCs), and mesenchymal stem and progenitor cells (MSCs) as well as very small embryonic-like stem cells [1] are found in circulation. These cells are able to differentiate into mature immune cells, endothelial cells, and cells of the connective tissue [2-4]. Given the physiologically important tasks of circulating stem and progenitor cells to repair and renew human tissue over the duration of an entire lifespan, and considering their promising application to treat a wide variety of degenerative conditions, research on potential stem cell mobilizing mechanisms is of great scientific interest [5].

Physical exercise as a non-invasive mechanism of adult stem and progenitor cell mobilization was first proposed around the 1980-ies with reports of increased hematopoietic stem and progenitor cell numbers (HSCs) measured in the peripheral blood after acute exercise [6-8]. An extensive and still growing body of literature has formed, reporting increased numbers not only of HSCs but also of circulating 
endothelial (ESCs) and mesenchymal (MSCs) stem and progenitor cells in the peripheral blood after physical activity [9-11]. However, several aspects of the study protocols make it difficult to understand mechanisms and kinetics. For example, exercise interventions differ substantially in type, intensity and duration, criteria for definition of the different cell subgroups as well as timepoints after exercise when cell numbers were assessed and also subject cohorts vary substantially between the different studies. Available reviews on this topic are either focused on a single cell population [12] and/or do not comply with current standards for systematic reviews [13-18]. Furthermore, to our knowledge, no comprehensive meta-analysis has yet been performed on this topic.

In the present study, we therefore conducted a comprehensive systematic review with meta-analyses on all available trials assessing numbers of early and non-specified adult stem and progenitor cells (enSCs) and respective SC-subgroups such as ESCs, HSCs, and MSCs in the peripheral blood, using flow cytometry or colony-forming-unit (CFU) assays before and at one or multiple timepoints after acute exercise. All reports conducted on healthy human subjects were included, regardless of the chosen study design. The main goal of the analysis was to assess whether and to which extent acute exercise mobilizes SCs and the different subgroups into the peripheral blood. As a secondary outcome, we aimed to identify possible moderating effects of sex, age, BMI and baseline physical activity level, as well as modality, duration, intensity and overall load of the exercise intervention.

\section{Methods}

The present systematic review and meta-analysis is reported according to the PRISMA statement [19] and its corresponding explanation and elaboration [20].

\section{Review Protocol}

The review question with the main and additional outcomes, as well as the strategy for the search, screening, extraction and analysis of the data were specified in advance. The review protocol can be made available upon request.

\section{Eligibility Criteria}

No restrictions were imposed regarding the design of the studies as randomization/blinding or control conditions are neither possible nor feasible in the context of the investigated interventions. Further, no language or publication date restrictions were applied. Non-primary literature such as reviews, editorials, cross talks and journal clubs were excluded. Posters, (conference) abstracts and study outlines with no full text publication available were excluded if crucial information was missing.
All studies including healthy human subjects of any age, sex, ethnicity, baseline physical activity level and BMI were considered. In studies including patients, data of healthy control subjects were assessed where available. If two studies reported the same outcome of an overlapping or identical cohort of subjects, only the study of higher relevance was included.

Only studies assessing effects of acute exercise were included. However, studies implementing acute exercise in combination with blood flow restriction, hypoxia, nutritional supplementation of any kind and/or infusion of drugs or other compounds, without a control arm performing exercise-only, were excluded. Also, training studies were excluded except for data assessed in the context of acute exercise prior to any training intervention.

Included studies were required to report sufficient information on the primary outcome which included numbers of enSCs and/or respective subgroups, i.e. ESCs, HSCs, and/or MSCs, in the peripheral blood assessed via flow cytometry or colony forming-unit (CFU) assays before and at least once after acute exercise.

Secondary outcome measures included moderator variables like sex, age, BMI and baseline physical activity level of the study cohort, as well as duration, intensity, load and modality of the exercise intervention. These variables were assessed as comprehensively as possible but failure to report any secondary measure did not result in exclusion of a study.

If a study failed to report adequate statistical information, it was excluded.

\section{Information Sources}

Electronic databases were screened via a computerized search of PubMed (MEDLINE database; 1966 to present), the Cochrane Library (1996 to present), EMBASE (1980 to present) and CINAHL (1961 to present) on 18 December 2018. A limited update search to identify newly published literature was performed in the form of 4 additional searches of the PubMed database between 18 and 2018 and 3 February 2020. In addition, citations and bibliographies of already positively qualified papers were hand searched.

\section{Search Strategy}

The search strategy was kept general and aimed at identifying all studies investigating stem and progenitor cells before and after acute exercise. Stricter inclusion criteria were applied during the subsequent selection process. This approach was chosen in order to minimize the risk of missing relevant literature. Keywords and Medical Subject Heading (MeSH) terms were kept very general and included expressions such as "exercise", "sport", "physical activity" for the intervention domain and "stem cells", "progenitor cells", "circulating cells" for the primary outcome domain. The search was applied to "All fields" and terms were combined with the logical operator OR within a domain and the logical operator 
AND between the domains. The detailed search strategy for each database can be made available upon request. The resulting list of publications was cross-validated for completeness using a composition of randomly pre-selected references, all of which needed to be successfully identified by the applied search strategy.

\section{Study Selection}

Eligibility was assessed independently by MS and JMK and consisted of a screening of the title, the abstract and the fulltext, sequentially excluding records failing to meet the predefined eligibility criteria (see also section "Study Selection"). Disagreements between the two reviewers were resolved by consensus.

\section{Data Collection Process}

A data extraction sheet was developed based on Harris et al., 2014 [21] and adapted to the primary and secondary outcome parameters at hand (see section "Data Items"). MS extracted the data of all included studies and JMK double checked the extracted data. Disagreements were resolved by discussion. If data points were accessible in graphical form only, MS and JMK independently extracted the data including error bounds using either the software PlotDigitizer version 2.6.8 [22] or by ruler and calculator. The average of the two separately extracted values $(\mathrm{CV}<0.1 \%)$ was computed and used for the metaanalysis.

\section{Data Items}

For each included publication, data was extracted on (1) general study information (author, journal, title, year of publication, year of patient enrollment, study design, country, possible conflicts of interest), (2) key statements (primary \& secondary purposes, hypotheses), (3) subject cohort (in- \& exclusion criteria, study rules, number of participants, sex, age, BMI, baseline physical activity level, smoking history, presence of a control group, medical history, ethnicity), (4) intervention (type/modality, duration, intensity, load, daytime of start, possible control interventions, several different interventions for the same participant group), (5) assessment of outcomes (procedure and timepoints of blood withdrawal, method of analysis (flow cytometry including the type of flow cytometer vs. CFU assay), method of cell isolation (lysis vs. density gradient centrifugation), cell surface marker combinations, cell estimates (relative number of cells present in \% mononuclear cells or lymphocytes and/or absolute number of cells per $\mu \mathrm{l}$ blood or number of CFUs at all measured timepoints before/after the intervention or an estimate of the change of circulating cell numbers pre to post)), and (6) statistical tests performed.

\section{Risk of Bias within Studies}

MS and JMK independently performed an individual risk of bias assessment for each included study, following a standardized checklist adapted from Moga et al., 2012 [23]. The checklist included 15 outcomes divided into the following categories: Study objective, Study population, Intervention, Outcome measures, Statistical analysis, Results and conclusion and Competing interests and source of support.

The assessment resulted in a quality score ranging from 0 to 15 points for each study. The final score for each study resulted from an average of the two separately assessed scores which did not differ more than a maximum of 3 score points. As none of the assessed studies yielded a score below 7.5 (50\% of the maximum reachable score) no publication had to be excluded due to insufficient quality. The full quality assessment checklist can be made available upon request.

\section{Summary Measures}

The measures extracted from the included studies were the absolute mean differences in cell numbers pre- to every measured timepoint post-exercise plus their standard deviations (SD) or the reported means of cell numbers pre- and postintervention including their SD. If publications reported standard errors only (SE), SD was calculated using the following formula, where $\mathrm{n}=$ number of subjects:

$S D=S E \times \sqrt{n}$

Data reported as median and range was converted to mean \pm SD using the approach proposed by Wan et al., 2014 [24].

The effect size for the assessment of the primary effect of acute exercise on circulating stem and progenitor cell numbers was the standardized difference in means (Std diff in means $\pm \mathrm{SE}$ or Std diff in means $\pm 95 \% \mathrm{CI}$ in the forest plots and analysis of bias across studies), as different studies reported the outcome in varying units. It was computed using the following formula:

Stddiff $=\frac{\text { Paireddiff }}{\frac{S D_{\text {Paireddiff }}}{\sqrt{2 \times(1-r)}}}$

where $\mathrm{r}=$ correlation coefficient and Paired diff $=$ paired mean difference, which was either given or calculated via:

Paireddiff $=$ mean $_{\text {post }}-$ mean $_{\text {pre }}$

and its respective standard deviation $\left(\mathrm{SD}_{\text {Paired diff }}\right)$ :

$S D_{\text {Paireddiff }}=\sqrt{\left(S D_{\text {pre }}\right)^{2}+\left(S D_{\text {post }}\right)^{2}-2 \times r \times S D_{\text {pre }} \times S D_{\text {post }}}$

Secondary outcomes were moderator variables such as age and sex of the study population. A comprehensive list of the assessed parameters including their definition is provided in Table 1. 
Table 1 Extracted moderator variables

\begin{tabular}{|c|c|}
\hline Variable & Definition \\
\hline Sex & Percentage of male participants \\
\hline Age & Mean age of participants in years. If the range was reported, the mean of the range was used \\
\hline BMI & Mean body mass index in $\mathrm{kg} \cdot \mathrm{m}^{-2}$ \\
\hline Modality & Exercise modality (running, cycling, resistance or other) \\
\hline Duration & Total exercise duration in minutes (with warm-up and cool-down not taken into account) \\
\hline Intensity & $\begin{array}{l}\text { Classified as } 1 \text { (low), } 2 \text { (moderate) or } 3 \text { (vigorous) according to Garber et al., } 2011 \text { [25]. If none of the } \\
\text { exercise measures were reported, the following criteria additionally applied: (half- )marathon/ultra-- } \\
\text { distance races, all-out/time trials, incremental tests to exhaustion }=3 \text {; exercise at } 100 \% \text { and above the } \\
\text { individual lactate/ventilatory or anaerobic threshold }=3 \text {, between } 70 \%-100 \%=2 \text {; exercise between } \\
0 \%-40 \% \text { of the individual peak power output/maximal work rate }=1,>40 \%-60 \%=2,>60 \%=3 \text {. }\end{array}$ \\
\hline Load & Product of duration $\times$ intensity \\
\hline Baseline physical activity level & $\begin{array}{l}\text { Classified as active or sedentary. "sedentary" = participants were described as sedentary, participants } \\
\text { engaged in less than } 0.5 \mathrm{~h} \text { of moderate activity } 3 \text { times/week [26], the reported } \mathrm{VO}_{2 \max } \text { was below the } \\
\text { age- and sex-specific average [27]. "active" = participants engaged in at least } 0.5 \mathrm{~h} \text { of moderate activity } \\
\text { at least } 3 \text { times/week, the reported } \mathrm{VO}_{2 \max } \text { was above the age- and sex-specific average. }\end{array}$ \\
\hline
\end{tabular}

\section{Statistical Analysis}

According to cell surface marker combinations, assessed outcomes were grouped into 4 major stem and progenitor cell subgroups: early and non-specified (i.e. not further characterized) stem and progenitor cells (enSCs), endothelial stem and progenitor cells (ESCs), hematopoietic stem and progenitor cells (HSCs) and mesenchymal stem and progenitor cells (MSCs). Only cells that were specifically reported to be positive for a clear indicator such as CD45 for the hematopoietic lineage [28] or KDR for ESCs [29] were allocated to the respective group. Cell populations only reported to positively stain for general stem cell markers such as CD34 [30] or CD133 [31], were-called "non-specified" stem and progenitor cells and allocated to the enSC-group. Populations that were positive for CD34 or CD133 but still negative for any of the lineage specific markers were called "early stem and progenitor cells" and allocated to the enSC-group as well. Within these cell subgroups, the outcomes were again subdivided into bins reflecting the various timepoints of post-exercise assessments. A list of the classification of the different marker combinations into the 4 subgroups, as well as the respective timepoint bins formed within the groups is provided in Table 2. The subgroups and respective timepoint combinations were established in an attempt to minimize co-occurrences of studies in the same bins while maximizing numbers of outcomes clustered in a bin.

If a study (measuring the same subject group during the same intervention) reported outcomes for multiple timepoints within the same bin and/or employed different marker combinations belonging to the same subgroup, a combined effect across outcomes was computed according to Borenstein et al., 2010 [32].
If a study conducted more than one intervention on the same or an overlapping cohort of subjects, or if a cell population was assessed using two different approaches that were not mergeable (i.e. flow cytometry and CFU assay), the sample size was divided and all outcomes were still taken into account for the analysis. This approach was deemed the most suitable, as it adjusts the weight of the study while making sure that no data points are lost.

For each bin in every cell subgroup, a separate meta-analysis was performed. All analyses were conducted using the Comprehensive Meta-Analysis Version 3 software (Biostat, Englewood, NJ, USA) applying a random effects model with paired groups. Weight of single studies was assigned with the inverse variance method. As correlation coefficients (r) were not reported in the primary literature, we used $r=0.6$, in regard of recommendations for imputing pre-to-post-correlations which vary between 0.5 [33] and 0.7 [34]. Heterogeneity was assessed using Chi-squared tests, $Q$ and $I^{2}$ statistics and statistical significance was set at $p<0.050$.

\section{Risk of Bias across Studies}

Publication bias due to studies reporting high effect sizes being more likely to be published and selective reporting within the published studies may affect the validity of the cumulative evidence [35]. We therefore assessed the risk of bias across studies in all analyses that included at least 20 effect sizes. In detail, the Std diff in means were plotted against their inversed standard errors, resulting in a funnel plot. Those plots were then tested for asymmetry using Egger's regression test and a Begg and Mazumdar rank correlation (yielding Kendall's tau, corrected for continuity). Additionally, Orwin's Fail - safe N with the criterion for an effect size deemed "trivial" set at a Std diff in means of 0.05 and assuming an effect size of 0.00 for 
Table 2 Outcome classification into groups and bins

\begin{tabular}{|c|c|c|}
\hline Cell Subgroup & Marker combinations/assays included & Timepoint bins \\
\hline enSCs & $\begin{array}{l}\mathrm{CD} 34^{+} \\
\mathrm{CD} 34^{+} / \mathrm{CD} 33^{-} \\
\mathrm{CD} 34^{+} / \mathrm{CD} 38^{-} \\
\mathrm{CD} 34^{+} / \mathrm{CD} 45^{-} \\
\mathrm{CD} 34^{+} / \mathrm{CD} 45^{-} / \mathrm{CD} 38^{-} \\
\mathrm{CD}^{+} 4^{+} / \mathrm{CD} 133^{+} \\
\mathrm{CD} 34^{+} / \mathrm{HLA}^{-} \mathrm{DR}^{-} \\
\mathrm{CD} 133^{+}\end{array}$ & 0-5 $\min , 6-20 \mathrm{~min}, 0.5 \mathrm{~h}, 1 \mathrm{~h}, 2 \mathrm{~h}, 3-96 \mathrm{~h}$ \\
\hline ESCs & 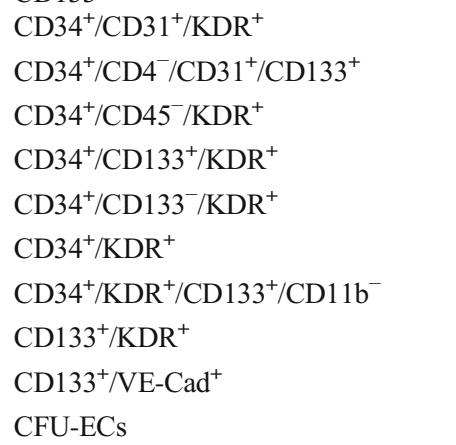 & $0-5 \mathrm{~min}, 6-20 \mathrm{~min}, 0.5 \mathrm{~h}, 1 \mathrm{~h}, 2 \mathrm{~h}, 3-8 \mathrm{~h}, 12-48 \mathrm{~h}$ \\
\hline HSCs & $\begin{array}{l}\mathrm{CD} 34^{+} / \mathrm{CD} 33^{+} \\
\mathrm{CD} 34^{+} / \mathrm{CD}^{+} 8^{+} \\
\mathrm{CD} 34^{+} / \mathrm{CD} 45^{+} \\
\mathrm{CD}^{+} 4^{+} / \mathrm{HLA}-\mathrm{DR}^{+} \\
\mathrm{CFU}-\mathrm{GM}\end{array}$ & $0-5 \min , 6-20 \min , 0.5 \mathrm{~h}, 1 \mathrm{~h}, 3 \mathrm{~h}, 12-24 \mathrm{~h}$ \\
\hline MSCs & $\begin{array}{l}\mathrm{CD} 34^{+} / \mathrm{CD} 45^{-} / \mathrm{CD} 31^{-} / \mathrm{CD} 105^{+} \\
\mathrm{CD} 34^{-} / \mathrm{CD} 45^{-} / \mathrm{CD} 31^{-} / \mathrm{CD} 105^{+} \\
\mathrm{CD} 45^{-} / \mathrm{CD} 29^{+} / \mathrm{CD} 13^{+}\end{array}$ & $0-5 \mathrm{~min}, 2 \mathrm{~h}$ \\
\hline
\end{tabular}

added studies, as well as Duval and Tweedies' trim and fill method (looking for missing studies to the left of the mean in a random effects model) were applied.

\section{Sensitivity Analyses}

In order to assess the magnitude of influence of every single effect size on the resulting cumulative effect size, one-studyremoved analyses (or in the present context more properly termed one-effect-size-removed analyses) were performed. Additionally, the robustness of the obtained cumulative effect sizes was tested by running the analyses again while substituting the imputed correlation coefficient of 0.6 by 0.5 and 0.7 . As a certain number of effect sizes are required for those tests to be meaningful, sensitivity analysis was conducted on all analyses calculated from at least 20 effect sizes.

\section{Moderator Variables}

The influence of the different moderator variables on the obtained effect sizes was tested via subgroup analysis for categorical variables (i.e. modality and intensity of the intervention and subjects' baseline physical activity level) or via meta-regression in the case of continuous, numerical variables (\%male participants, age, BMI, duration and load of the intervention).

For subgroup analyses, the heterogeneity between effect sizes within a subgroup was computed using Q tests based on analysis of variance. A fully random effects model was used and study-to-study variance was assumed to be equal for all studies and was thus pooled across all studies.

Meta-regressions were performed by plotting the magnitude of the variable versus the magnitude of the effect size while using a separate model for each variable. Prediction capacity of the moderator was tested using a simultaneous test that all coefficients (excluding intercept) are zero.

Subject and intervention characteristics are reported as mean \pm SD. All tests were pre-defined and statistical significance was set at $p<0.050$. Analyses were performed whenever at least 20 effect sizes were available and the main analysis revealed a significant $(p<0.050)$ heterogeneity of at least $I^{2} \geq 50 \%$ among the included effect sizes. 


\section{Results}

\section{Study Selection}

A total of 55 studies, resulting in 285 different effect sizes, were included in the review and meta-analysis. The initial search yielded 4088 records, of which 1457 were duplicates. Of the remaining 2631 records, 2017 were excluded due to their title being off-topic. 612 records were further considered and their abstracts screened for exclusion criteria. The remaining 97 publications were screened in full-text, where another 47 failed to meet the eligibility criteria and consequently were excluded. 50 studies were finally considered with another 5 studies additionally included in hindsight due to reference list screening of included papers and new publications being identified in the follow-up searches. Figure 1 depicts the selection process.

\section{Study Characteristics}

A summary of extracted data for all included studies can be found in Table 3.
Fig. 1 Flow diagram of the selection process

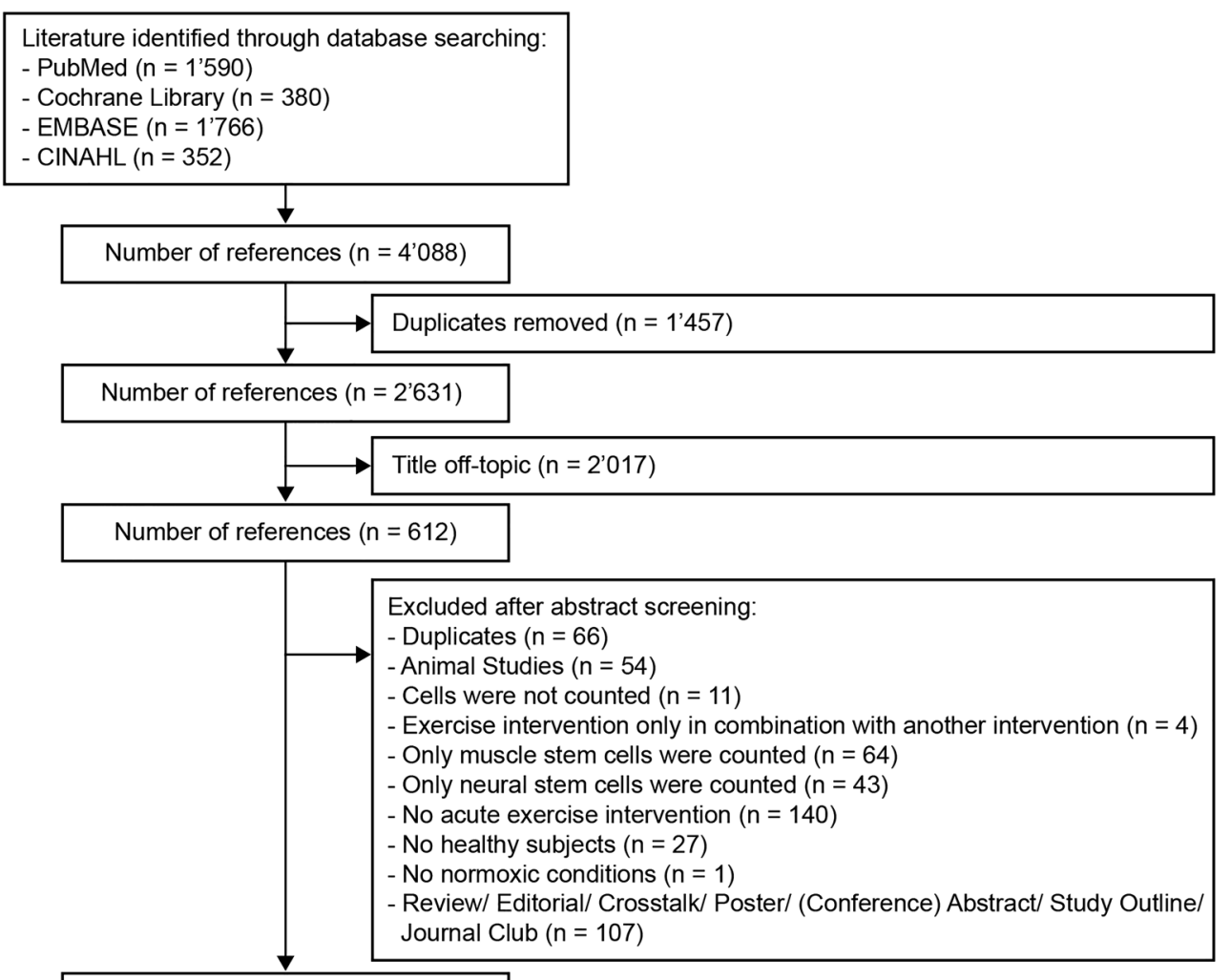

Number of references $(n=97)$ 


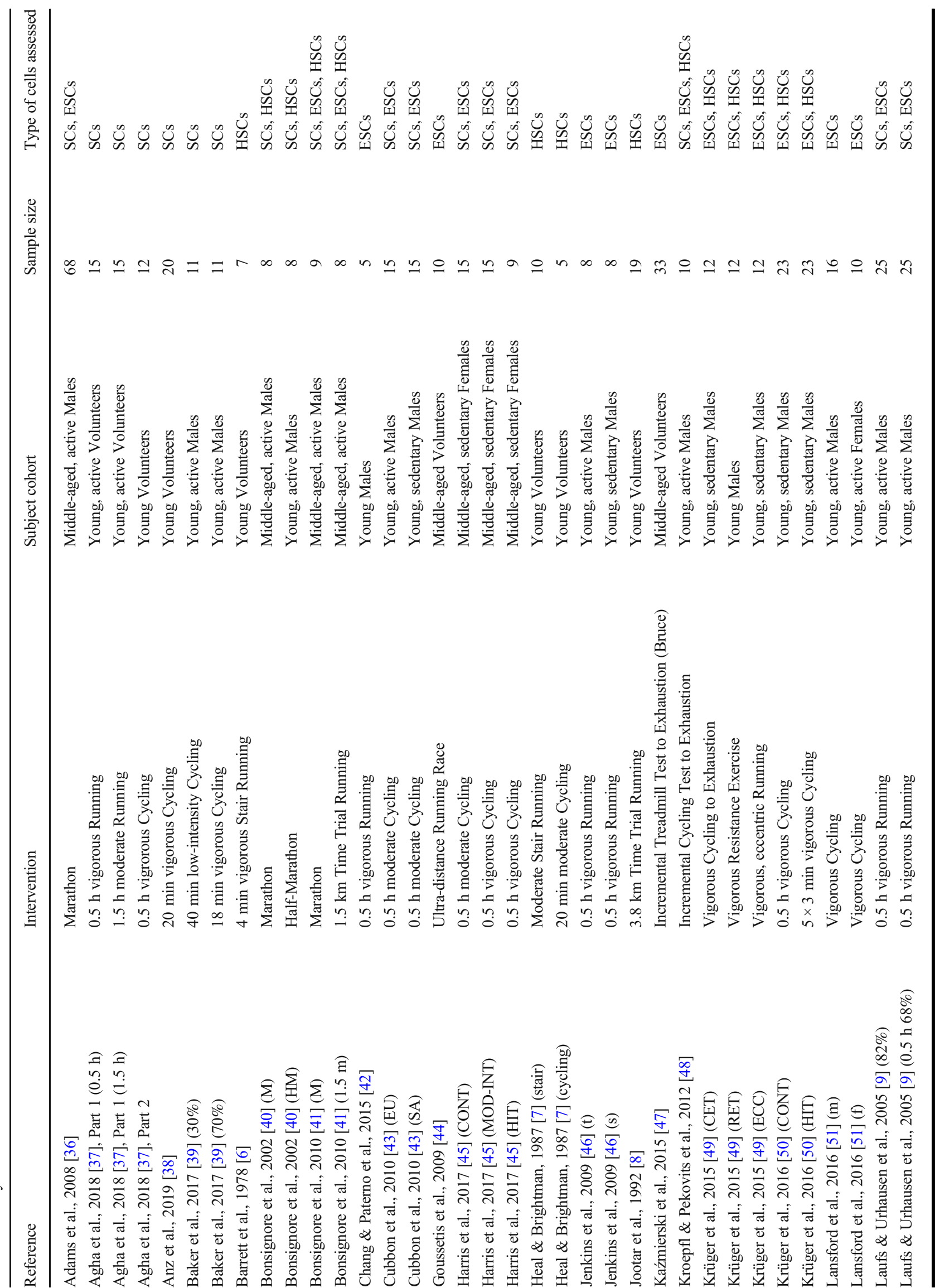




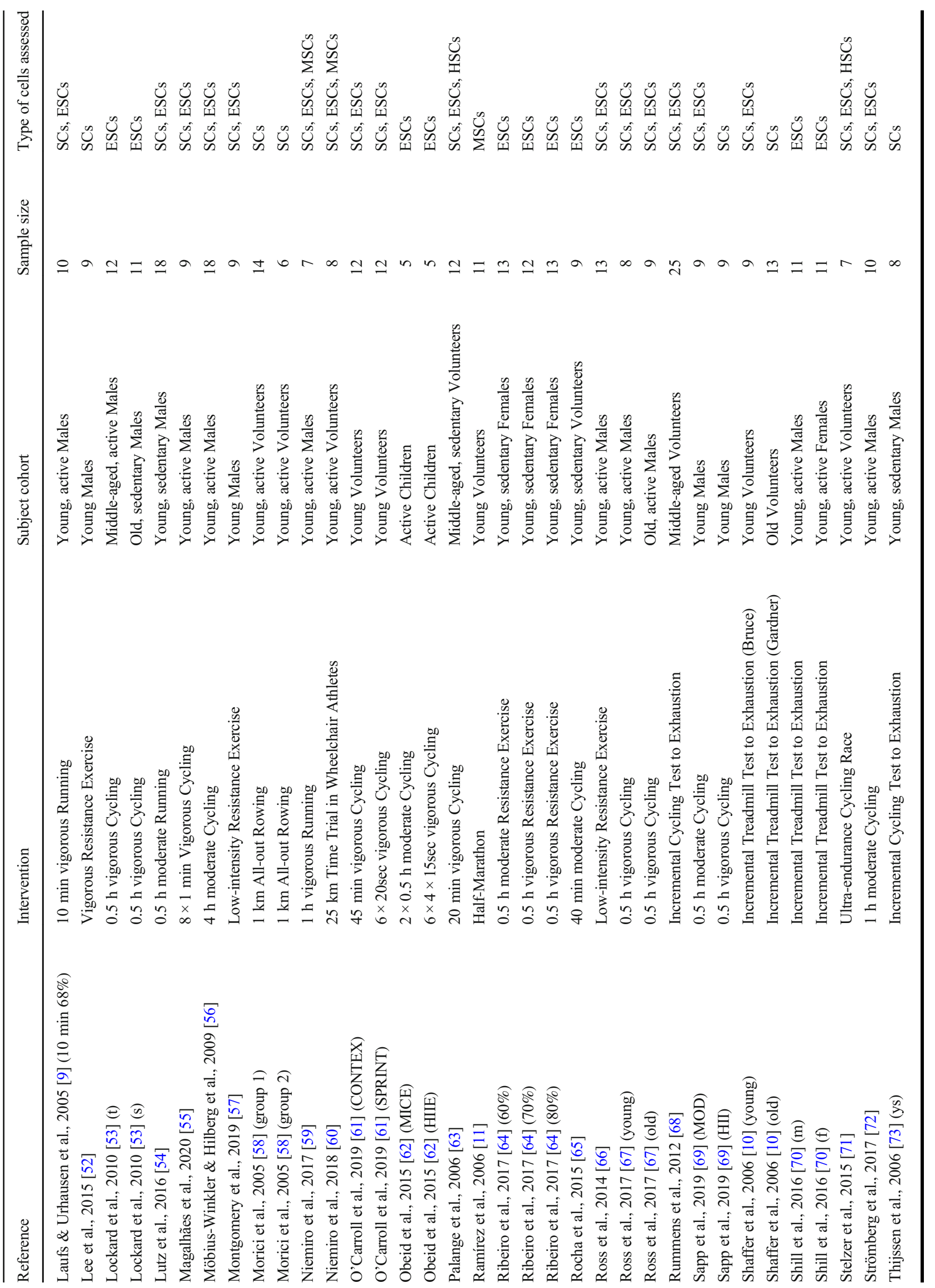




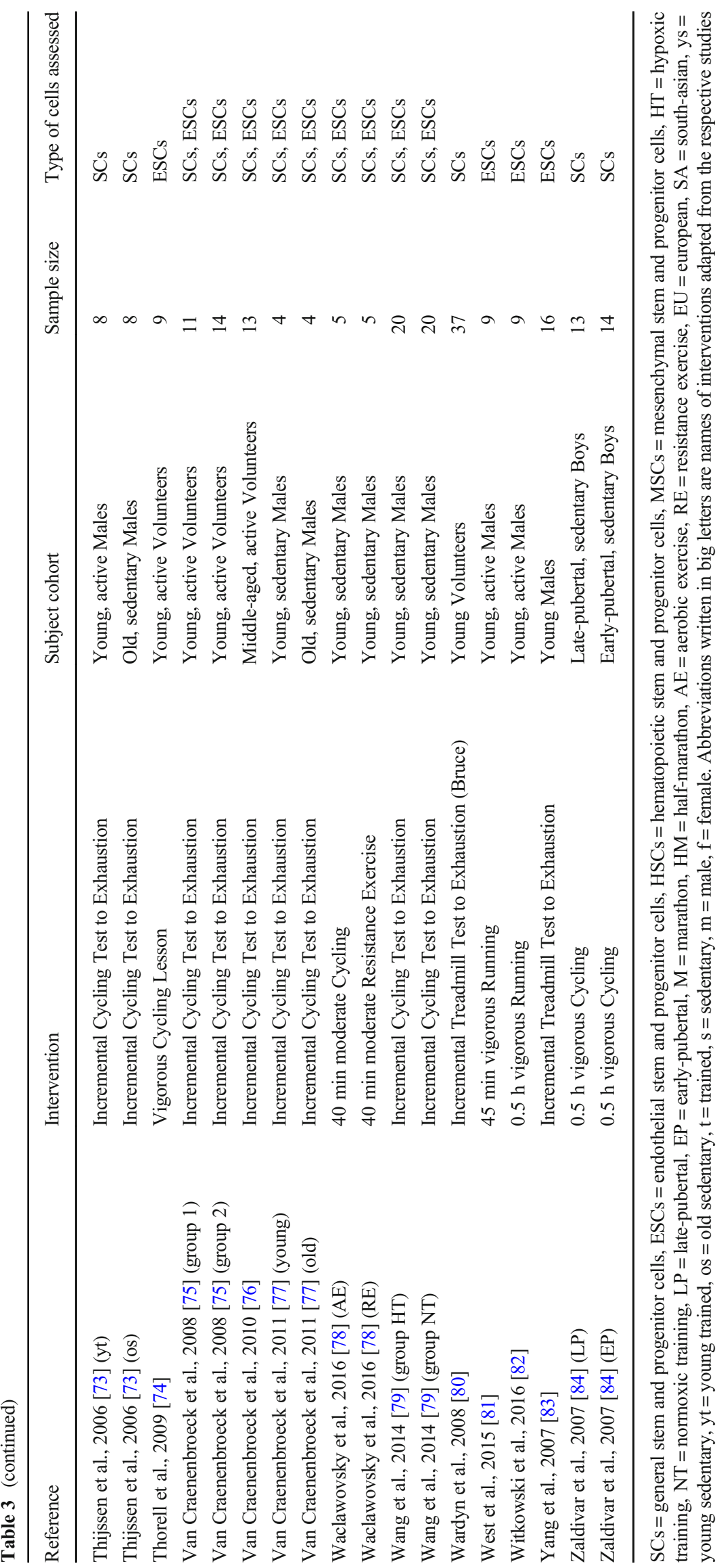




\section{Risk of Bias within Studies (Quality Assessment)}

The individual risk of bias within each included study is shown in Table 4, which shows the total quality score assessed using the aforementioned standardized checklist. The average score $( \pm \mathrm{SD})$ was $10.9 \pm 1.3$, with a range of 7.5-13.0. All studies reported their study objective, while only $80 \%$ sufficiently described the characteristics of the study cohort. $38 \%$ failed to impose explicit in- and exclusion criteria or the reporting thereof and none of the included studies recruited their participants consecutively while appropriately stating to do so. A clear and complete description of the study intervention was provided by $76 \%$ of studies. $98 \%$ clearly defined their outcome parameters, used appropriate methods to determine them and measured outcomes before and after the intervention. $98 \%$ further used adequate statistical tests to assess the relevant outcomes. All studies reported the length of follow up (latest timepoint of assessment) but only $18 \%$ reported the loss of follow-up. $91 \%$ provided comprehensive estimates of the random variability, while only $4 \%$ reported whether any adverse events had occurred. Conclusions of all studies were supported by the obtained results and $60 \%$ of the studies stated sources of funding and whether competing interests existed.

\section{Results of Individual Studies}

Following, forest plots and individual results of meta-analyses for all timepoints/bins within the assessed stem and progenitor cell populations are reported. Forest plots depict effect sizes which are Std diff in means $(95 \% \mathrm{CI})$, calculated from cell numbers measured before and at/within the indicated timepoint/-span after exercise. The weight of each effect size is represented by the size of its corresponding symbol. The combined data is always shown in the last row.

\section{Early and Non-specified Stem and Progenitor Cells (enSCs)}

In the $0-5 \mathrm{~min}$ bin, a total of 27 effect sizes, with 344 subjects $(87.7 \pm 19.2 \%$ male, $31.2 \pm 13.9$ years old, BMI of $23.9 \pm 1.9$ $\mathrm{kg} \cdot \mathrm{m}^{-2}$ ) were included in the meta-analysis. The exercise interventions had a mean duration of $2.2 \pm 6.6 \mathrm{~h}$ at an intensity of $2.7 \pm 0.6$. The combined Std diff in means $( \pm \mathrm{SE})$ showed a significant overall increase in enSCs directly after exercise $(0.64 \pm 0.16, p<0.001$; Fig. 2a).

The 6-20 min bin included 29 effect sizes, with an overall number of 284 subjects $(91.5 \pm 6.4 \%$ male, $32.9 \pm 15.4$ years old, BMI of $23.4 \pm 1.0 \mathrm{~kg} \cdot \mathrm{m}^{-2}$ ) and exercise interventions lasting on average $42.7 \pm 53.9 \mathrm{~min}$ at an intensity of $2.7 \pm$ 0.6 . The combined Std diff in means was $0.42 \pm 0.11$ $(p<0.001$, Fig. 2b).
At $0.5 \mathrm{~h}$ after exercise, 12 effect sizes were assessed. This resulted in 99 subjects $(75 \pm 45.2 \%$ male, $38.3 \pm 20.2$ years old, BMI of $24.0 \pm 1.2 \mathrm{~kg} \cdot \mathrm{m}^{-2}$ ). On average, exercise interventions lasted $55.4 \pm 70.3 \mathrm{~min}$ at an intensity of $2.3 \pm 0.8$. Cell numbers increased significantly pre- to $0.5 \mathrm{~h}$ post-exercise, as indicated by a combined Std diff in means of $0.29 \pm$ 0.15 ( $p=0.049$, Fig. 2c).

At $1 \mathrm{~h}$ after exercise, 10 effect sizes, including 81 subjects $(89.0 \pm 19.5 \%$ male, $30.9 \pm 14.7$ years old, BMI of $24.0 \pm 1.3 \mathrm{~kg}$. $\mathrm{m}^{-2}$ ) were included. Exercise interventions lasted on average $1.1 \pm 1.2 \mathrm{~h}$ at a mean intensity of $2.6 \pm 0.7$. The combined Std diff in means was not significant $(0.55 \pm 0.28, p=0.053$; Fig. 2d).

At $2 \mathrm{~h}$ after exercise, 12 effect sizes, including 102 subjects $(86.7 \pm 20.1 \%$ male, $30.4 \pm 13.3$ years old, BMI of $24.0 \pm 1.3$ $\mathrm{kg} \cdot \mathrm{m}^{-2}$ ) were analysed. The average intervention lasted $1.1 \pm$ $1.2 \mathrm{~h}$ at an intensity of $2.6 \pm 0.7$. The combined Std diff in means revealed no significant change in cell numbers compared to baseline $(0.21 \pm 0.17, p=0.209$; Fig. $2 \mathrm{e})$.

At 3-96 h after exercise, 12 effect sizes, with a total of 100 subjects $(86.7 \pm 20.1 \%$ male, $34.7 \pm 14.3$ years old, BMI of $24.0 \pm 1.3 \mathrm{~kg} \cdot \mathrm{m}^{-2}$ ) were analysed. Mean exercise time was $1.7 \pm 1.5 \mathrm{~h}$ at an intensity of $2.7 \pm 0.7$. The combined Std diff in means was not significant $(0.06 \pm 0.14, p=0.682$; Fig. 2 f) .

\section{Endothelial Stem and Progenitor Cells (ESCs)}

At $0-5$ min after exercise, 34 effect sizes, with an overall number of 410 subjects $(73.8 \pm 40.0 \%$ male, $30.1 \pm$ 13.2 years old, BMI of $23.5 \pm 1.8 \mathrm{~kg} \cdot \mathrm{m}^{-2}$ ) were included in the meta-analysis of ESCs. Subjects exercised $2.8 \pm$ $7.9 \mathrm{~h}$ on average at an intensity of $2.8 \pm 0.5$. This resulted in a significant combined Std diff in means of $0.66 \pm 0.11$ $(p<0.001$, Fig. 3a).

At 6-20 min after exercise, 31 effect sizes were analysed. The 252 included subjects $(93.2 \pm 14.1 \%$ male, $34.1 \pm 14.1$ years old, BMI of $23.6 \pm 1.4 \mathrm{~kg} \cdot \mathrm{m}^{-2}$ ) exercised on average $43.2 \pm 49.4 \mathrm{~min}$ at an intensity of $2.8 \pm 0.5$. The combined Std diff in means showed a significant increase in cell numbers $(0.43 \pm 0.11$, $p<0.001$, Fig. 3b).

At $0.5 \mathrm{~h}$ after exercise, 19 effect sizes, with 133 subjects ( $68.4 \pm 47.8 \%$ male, $47.6 \pm 19.9$ years old, BMI of $23.8 \pm 1.3$ $\mathrm{kg} \cdot \mathrm{m}^{-2}$ ) were included. After a mean exercise time of $43.7 \pm$ $53.2 \mathrm{~min}$ at an intensity of $2.6 \pm 0.6$, the combined Std diff in means showed a significant increase of a point estimate of $0.43 \pm 0.14$ ( $p=0.002$, Fig. $3 c)$.

At $1 \mathrm{~h}$ after exercise, 7 effect sizes, including 84 subjects $\left(86.3 \pm 29.1 \%\right.$ male, $35.6 \pm 17.2$ years old, $23.9 \pm 2.4 \mathrm{~kg} \cdot \mathrm{m}^{-2}$ BMI) were analysed. The interventions lasted $1.6 \pm 1.6 \mathrm{~h}$ on average at a mean intensity of $2.9 \pm 0.4$. Combined Std diff in means showed a significant increase in cell numbers $1 \mathrm{~h}$ after exercise $(0.58 \pm 0.17, p=0.001$; Fig. $3 \mathrm{~d})$. 
Table 4 Quality assessment

\begin{tabular}{|c|c|}
\hline Reference & Quality Score (0-15) \\
\hline Adams et al., 2008 [36] & $11 \pm 0.0$ \\
\hline Agha et al., 2018 [37] & $12.5 \pm 0.7$ \\
\hline Anz et al., 2019 [38] & $9.5 \pm 0.7$ \\
\hline Baker et al., 2017 [39] & $11.5 \pm 0.7$ \\
\hline Barrett et al., 1978 [6] & $8 \pm 0.0$ \\
\hline Bonsignore et al., 2002 [40] & $11.5 \pm 2.1$ \\
\hline Bonsignore et al., 2010 [41] & $9.5 \pm 0.7$ \\
\hline Chang \& Paterno et al., 2015 [42] & $10 \pm 0.0$ \\
\hline Cubbon et al., 2010 [43] & $11 \pm 1.4$ \\
\hline Goussetis et al., 2009 [44] & $10.5 \pm 2.1$ \\
\hline Harris et al., 2017 [45] & $11.5 \pm 2.1$ \\
\hline Heal \& Brightman, 1987 [7] & $9 \pm 0.0$ \\
\hline Jenkins et al., 2009 [46] & $10.5 \pm 0.7$ \\
\hline Jootar et al., 1992 [8] & $7.5 \pm 2.1$ \\
\hline Kaźmierski et al., 2015 [47] & $11 \pm 1.4$ \\
\hline Kroepfl \& Pekovits et al., 2012 [48] & $12 \pm 0.0$ \\
\hline Krüger et al., 2015 [49] & $10.5 \pm 0.7$ \\
\hline Krüger et al., 2016 [50] & $12 \pm 0.0$ \\
\hline Lansford et al., 2016 [51] & $12 \pm 0.0$ \\
\hline Laufs \& Urhausen et al., 2005 [9] & $10.5 \pm 0.7$ \\
\hline Lee et al., 2015 [52] & $12.5 \pm 0.7$ \\
\hline Lockard et al., 2010 [53] & $12.5 \pm 0.7$ \\
\hline Lutz et al., 2016 [54] & $12 \pm 0.0$ \\
\hline Magalhães et al., 2020 [55] & $13 \pm 0.0$ \\
\hline Möbius-Winkler \& Hilberg et al., 2009 [56] & $10.5 \pm 2.1$ \\
\hline Montgomery et al., 2019 [57] & $12 \pm 0.0$ \\
\hline Morici et al., 2005 [58] & $11.5 \pm 0.7$ \\
\hline Niemiro et al., 2017 [59] & $12.5 \pm 0.0$ \\
\hline Niemiro et al., 2018 [60] & $12 \pm 2.1$ \\
\hline O'Carroll et al., 2019 [61] & $10 \pm 0.0$ \\
\hline Obeid et al., 2015 [62] & $11.5 \pm 0.7$ \\
\hline Palange et al., 2006 [63] & $10 \pm 0.0$ \\
\hline Ramírez et al., 2006 [11] & $9.5 \pm 0.7$ \\
\hline Ribeiro et al., 2017 [64] & $13 \pm 0.0$ \\
\hline Rocha et al., 2015 [65] & $11 \pm 0.0$ \\
\hline Ross et al., 2014 [66] & $11 \pm 0.7$ \\
\hline Ross et al., 2017 [67] & $10.5 \pm 0.0$ \\
\hline Rummens et al., 2012 [68] & $11 \pm 0.0$ \\
\hline Sapp et al., 2019 [69] & $13 \pm 0.0$ \\
\hline Shaffer et al., 2006 [10] & $8 \pm 1.4$ \\
\hline Shill et al., 2016 [70] & $11.5 \pm 0.7$ \\
\hline Stelzer et al., 2015 [71] & $12 \pm 1.4$ \\
\hline Strömberg et al., 2017 [72] & $11.5 \pm 0.7$ \\
\hline Thijssen et al., 2006 [73] & $10.5 \pm 0.7$ \\
\hline Thorell et al., 2009 [74] & $10.5 \pm 0.7$ \\
\hline Van Craenenbroeck et al., 2008 [75] & $11 \pm 0.0$ \\
\hline Van Craenenbroeck et al., 2010 [76] & $10 \pm 0.0$ \\
\hline Van Craenenbroeck et al., 2011 [77] & $10 \pm 0.0$ \\
\hline Waclawovsky et al., 2016 [78] & $11.5 \pm 0.7$ \\
\hline
\end{tabular}

Table 4 (continued)

Reference

Quality Score (0-15)

\begin{tabular}{lr}
\hline Wang et al., 2014 [79] & $12 \pm 1.4$ \\
Wardyn et al., 2008 [80] & $8 \pm 0.0$ \\
West et al., 2015 [81] & $13 \pm 1.4$ \\
Witkowski et al., 2016 [82] & $11.5 \pm 0.7$ \\
Yang et al., 2007 [83] & $10 \pm 0.0$ \\
Zaldivar et al., 2007 [84] & $11 \pm 0.0$
\end{tabular}

Quality score is displayed as mean $\pm \mathrm{SD}$

At $2 \mathrm{~h}$ after exercise, 8 effect sizes, with a total of 68 subjects $(91.7 \pm 15.4 \%$ male, $31.9 \pm 16.5$ years old, BMI of $24.2 \pm 1.5 \mathrm{~kg}$. $\mathrm{m}^{-2}$ ) were included in the meta-analysis of ESCs. Interventions lasted on average $1.2 \pm 1.4 \mathrm{~h}$ at an intensity of $2.5 \pm 0.8$ and a significant combined Std diff in means of $0.50 \pm 0.16(p=0.002$, Fig. 3e) was found.

At 3-8 $\mathrm{h}$ after exercise, 10 effect sizes, including a total of 105 subjects $(70.0 \pm 48.3 \%$ male, $28.4 \pm 15.4$ years old, BMI of $23.3 \pm 1.3 \mathrm{~kg} \cdot \mathrm{m}^{-2}$ ) were analysed. Exercise interventions lasted on average $27.5 \pm 2.8 \mathrm{~min}$ at an intensity of $2.9 \pm 0.3$. The analysis resulted in a significant increase indicated by a combined Std diff in means of $0.70 \pm 0.15$ $(p<0.001$, Fig. 3f).

At $12-48 \mathrm{~h}$ after exercise, 21 effect sizes, with 190 subjects $(77.8 \pm 38.7 \%$ male, $30.7 \pm 11.7$ years old, BMI of $23.8 \pm 1.3$ $\mathrm{kg} \cdot \mathrm{m}^{-2}$ ) were included. They involved $2.6 \pm 7.2 \mathrm{~h}$ of exercise at an intensity of $2.8 \pm 0.5$ on average. Results showed a significant combined Std diff in means ( 0.38 $\pm 0.13, p=0.003$, Fig. 3g).

\section{Hematopoietic Stem and Progenitor Cells (HSCs)}

At 0-5 min after exercise, 16 analysed effect sizes included a total of 127 subjects $(86.2 \pm 21.0 \%$ male, $33.8 \pm 12.6$ years old, BMI of $24.4 \pm 0.8 \mathrm{~kg} \cdot \mathrm{m}^{-2}$ ). Exercise lasted on average $2.4 \pm 7.9 \mathrm{~h}$ at an intensity of $2.9 \pm 0.3$. The combined Std diff in means of $0.47 \pm 0.10$ represents a significant overall increase in HSC number directly after exercise $(p<0.001$, Fig. 4a).

At 6-20 min after exercise, 8 effect sizes, resulting in a total of 69 subjects $(84.7 \pm 23.6 \%$ male, $34.2 \pm 8.7$ years old, BMI $23.2 \pm 0.3 \mathrm{~kg} \cdot \mathrm{m}^{-2}$ ) were included. The average intervention lasted $1.2 \pm 1.4 \mathrm{~h}$ at an intensity of $2.8 \pm 0.5$. No significant combined Std diff in means was found $(-0.28 \pm 0.20, p=$ 0.171 ; Fig. 4b).

At $0.5 \mathrm{~h}$ after exercise, 3 effect sizes, including 34 subjects ( $59.3 \pm 20.0 \%$ male, $31.8 \pm 1.2$ years old) were analysed. The average exercise intervention lasted $13.5 \pm 10.3 \mathrm{~min}$ at an intensity of $2.3 \pm 0.6$. The combined Std diff in means showed 
a

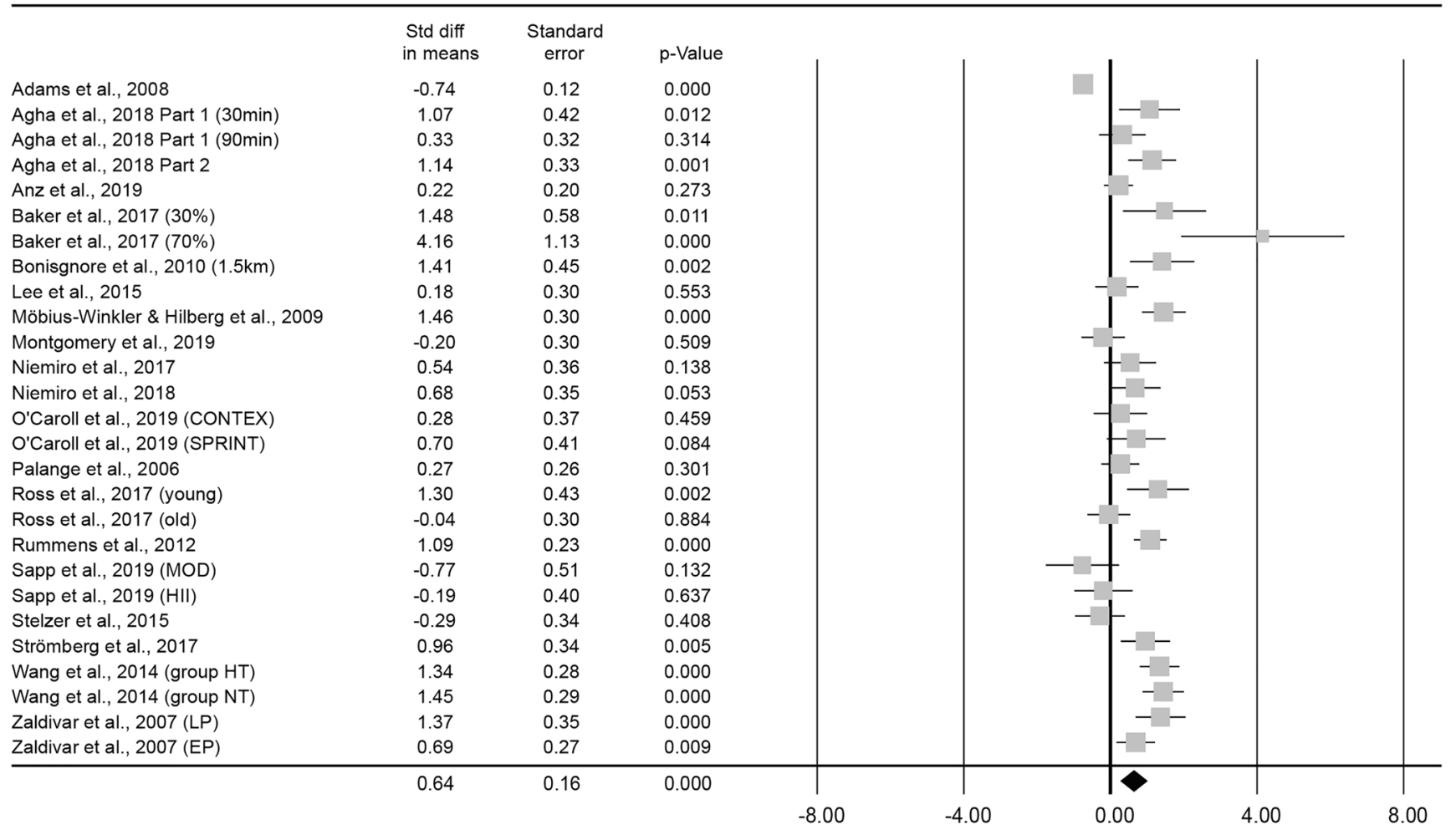

b

Reference

Statistics for each study

Std diff in means and $95 \% \mathrm{Cl}$

Baker et al., 2017 (30\%)

Baker et al., 2017 (70\%)

Bonsignore et al., 2002 (M)

Bonsignore et al., 2002 (HM)

Bonisgnore et al., $2010(\mathrm{M})$

Cubbon et al., 2010 (EU)

Cubbon et al., 2010 (SA)

Kröpfl \& Pekovits et al., 2012

Laufs \& Urhausen et al., 2005 (82\%)

Laufs \& Urhausen et al., 2005 (30min 68\%)

Laufs \& Urhausen et al., 2005 (10min 68\%)

Magalhaes et al., 2020

Morici et al., 2005 (group 1)

Morici et al., 2005 (group 2)

Niemiro et al., 2017

Ross et al., 2014

Shaffer et al., 2006 (young)

Shaffer et al., 2006 (old)

Thijssen et al., 2006 (ys)

Thijssen et al., 2006 (yt)

Thijssen et al., 2006 (os)

Van Craenenbroeck et al., 2008 (group 1)

Van Craenenbroeck et al., 2008 (group 2)

Van Craenenbroeck et al., 2010

Van Craenenbroeck et al., 2011 (young)

Van Craenenbroeck et al., 2011 (old)

Waclawovsky et al., 2016 (AE)

Waclawovsky et al., 2016 (RE)

Wardyn et al., 2008

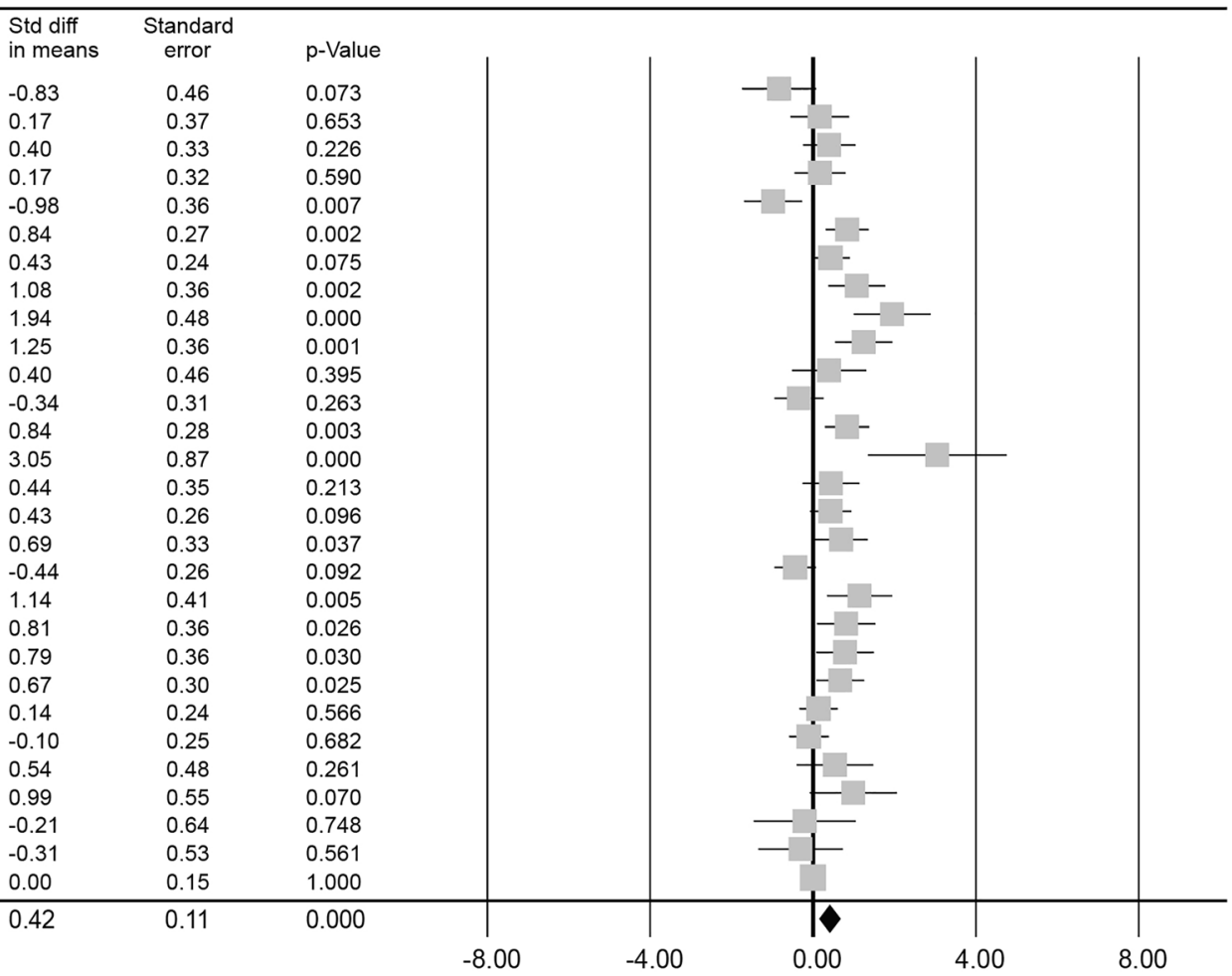

Fig. 2 Forest plot of enSCs 0-5 $\min (\mathbf{a}), 6-20 \mathrm{~min}(\mathbf{b}), 0.5 \mathrm{~h}(\mathbf{c}), 1 \mathrm{~h}(\mathbf{d}), 2 \mathrm{~h}(\mathbf{e})$ and 3-96 h post-exercise $(\mathbf{f})$. Std diff $=$ standardized difference, CI = confidence interval 
C

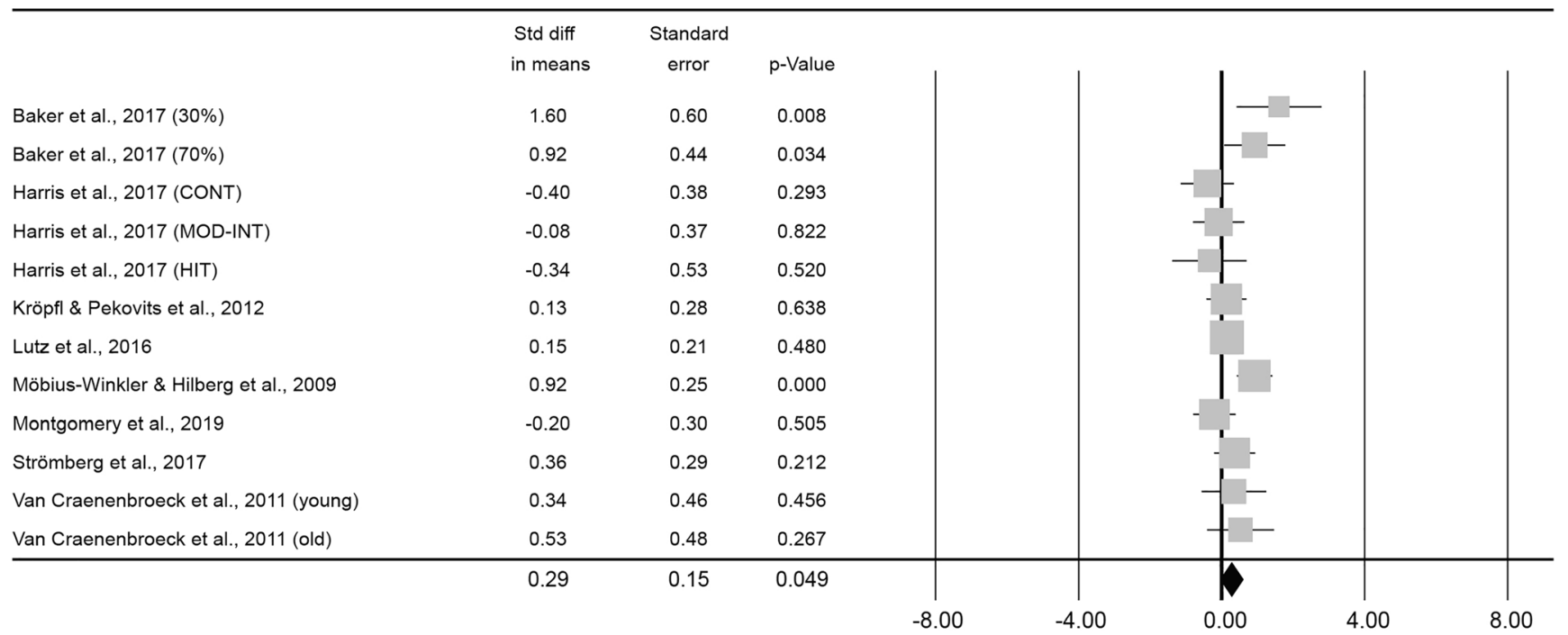

d

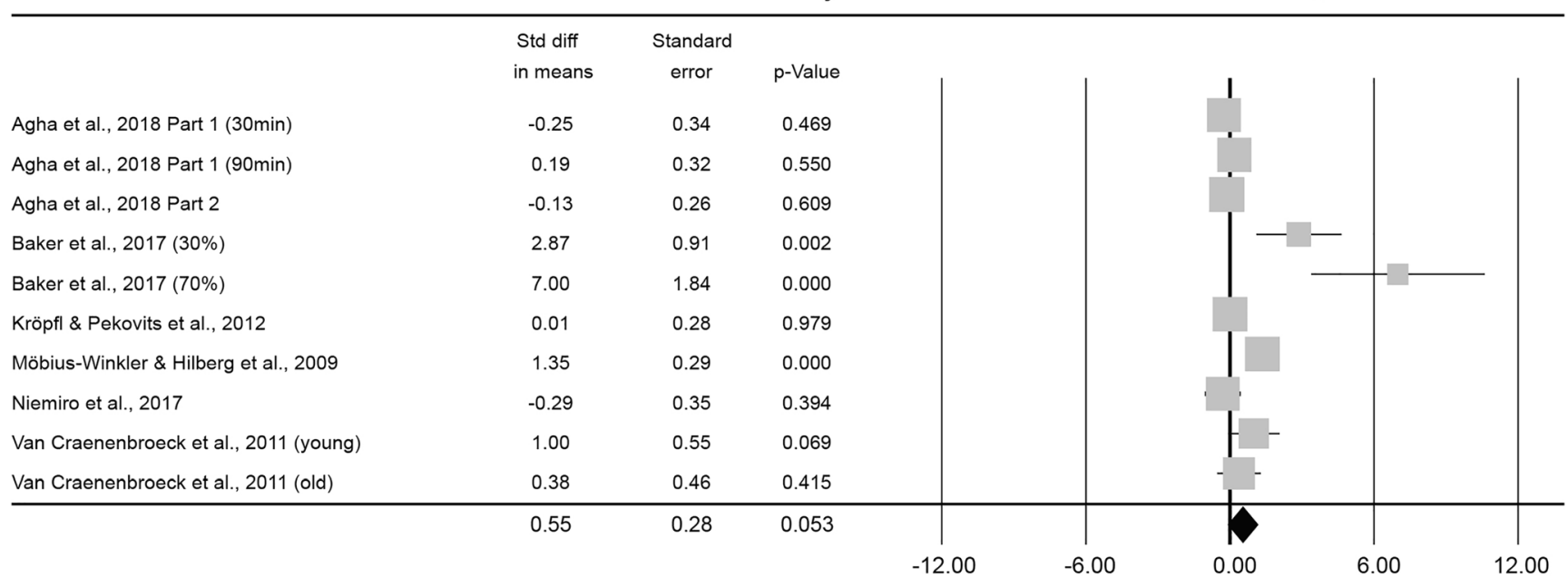

Fig. 2 (continued)

no changes in HSC numbers $0.5 \mathrm{~h}$ after exercise compared to baseline $(0.10 \pm 0.15, p=0.524$; Fig. $4 \mathrm{c})$. No information was provided on subjects' BMI or height/weight.

At $1 \mathrm{~h}$ after exercise, another 3 effect sizes, including a total of 84 subjects ( $59.3 \pm 20.0 \%$ male, $31.8 \pm 1.2$ years old) were analysed. On average, exercise interventions lasted $13.5 \pm$ $10.3 \mathrm{~min}$ at a mean intensity of $2.3 \pm 0.6$. The analysis of the combined Std diff in means found no significant effect of exercise on circulating HSC numbers measured $1 \mathrm{~h}$ after exercise $(-0.23 \pm 0.16, p=0.142$; Fig. $4 d)$. No information was provided on subjects' BMI or height/weight.

At $3 \mathrm{~h}$ after exercise, 8 effect sizes included a total of 59 subjects $(100.0 \pm 0.0 \%$ male, $25.9 \pm 0.4$ years old, BMI of $\left.24.2 \pm 0.2 \mathrm{~kg} \cdot \mathrm{m}^{-2}\right)$. The average intervention lasted $39.2 \pm$
$22.8 \mathrm{~min}$ and was conducted at a vigorous intensity of $3.0 \pm$ 0.0 . The analysis found a significant combined Std diff in means $3 \mathrm{~h}$ post-exercise $(0.68 \pm 0.13, p<0.001$; Fig. $4 \mathrm{e})$.

At $12-24 \mathrm{~h}$ after exercise, 11 effect sizes, with 84 subjects $(100.0 \pm 0.0 \%$ male, $30.4 \pm 8.6$ years old, BMI of $24.0 \pm 0.4$ $\mathrm{kg} \cdot \mathrm{m}^{-2}$ ) were included. After an average intervention of 1.2 $\pm 1.1 \mathrm{~h}$ exercising at an intensity of $3.0 \pm 0.0$, the combined Std diff in means showed no significant change in HSC numbers $(0.27 \pm 0.17, p=0.107$; Fig. $4 \mathrm{f})$.

\section{Mesenchymal Stem and Progenitor Cells (MSCs)}

At $0-5$ min after exercise, 2 effect sizes were reported, resulting in a total of 15 subjects $(81.3 \pm 26.5 \%$ male, $26.4 \pm$ 
e

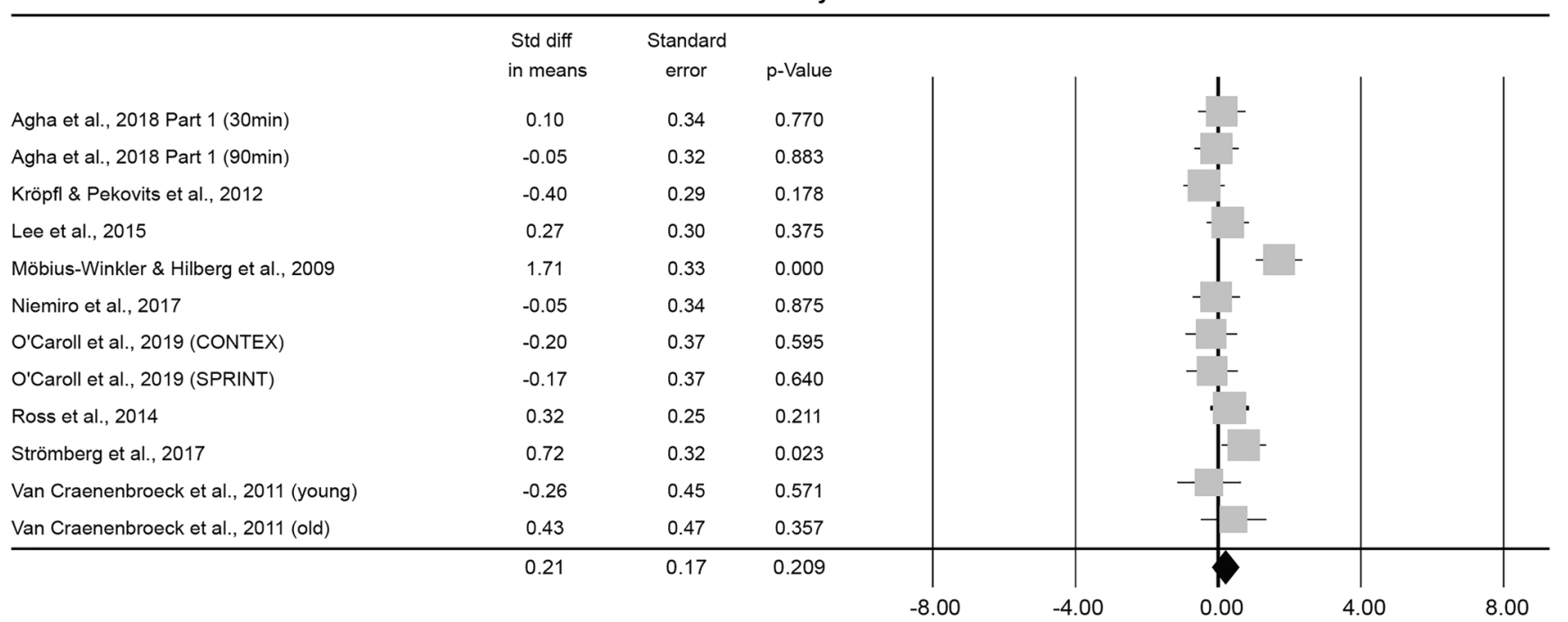

f

Reference

Statistics for each study

Std diff in means and $95 \% \mathrm{Cl}$

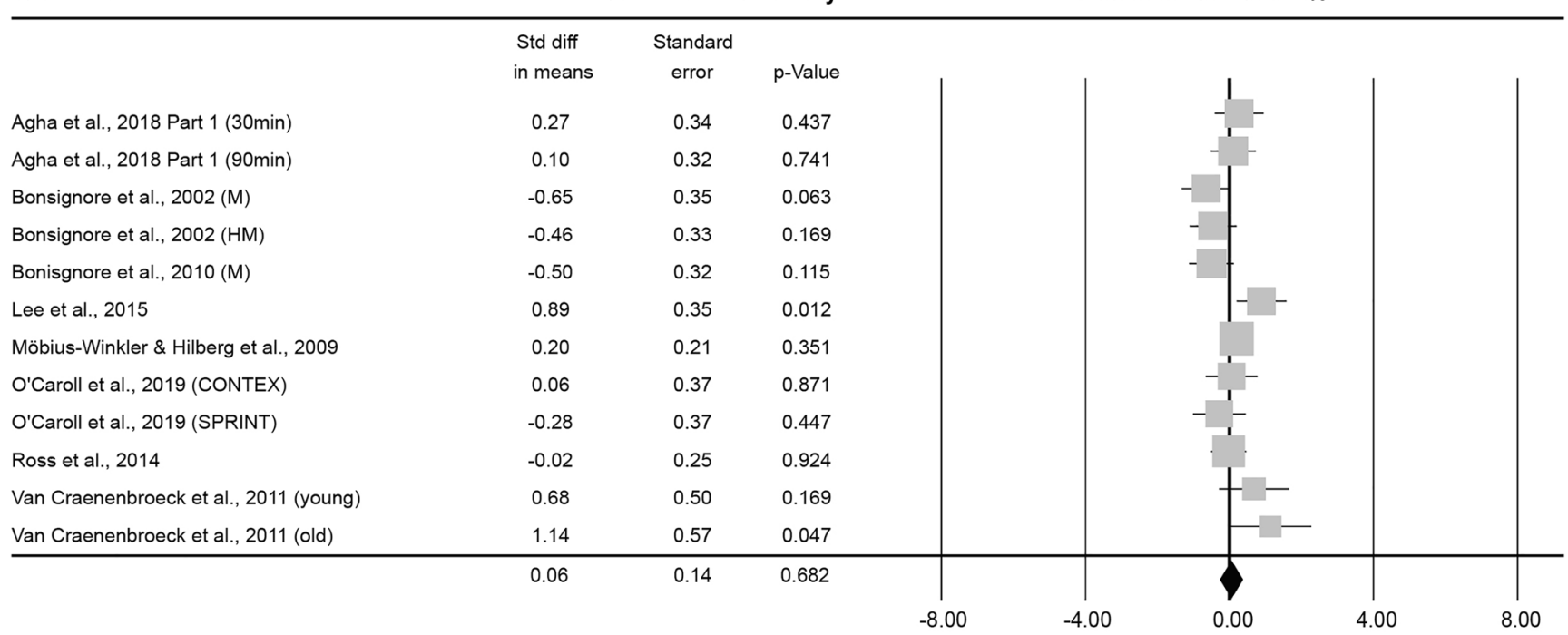

Fig. 2 (continued)

1.6 years old, BMI of $21.9 \pm 2.3 \mathrm{~kg} \cdot \mathrm{m}^{-2}$ ). Interventions lasted on average $56.0 \pm 5.7 \mathrm{~min}$ and were conducted at a vigorous intensity of $3.0 \pm 0.0$. The combined Std diff in means indicated no significant change in cell numbers $(-0.37 \pm 0.24, p=$ 0.128; Fig. 5a).

At $2 \mathrm{~h}$ after exercise, 2 effect sizes, with 18 subjects $(100.0 \pm 0.0 \%$ male, $30.2 \pm 6.9$ years old, BMI of $23.5 \pm$ $0.0 \mathrm{~kg} \cdot \mathrm{m}^{-2}$ ). Interventions had a mean duration of $1.0 \pm$ $0.0 \mathrm{~h}$ and were conducted at an intensity of $3.0 \pm 0.0$. The analysis of the combined Std diff in means showed no effect of exercise on MSC numbers $2 \mathrm{~h}$ post-intervention $(0.23 \pm 0.75, p=0.761$; Fig. $5 b)$.

\section{Synthesis of Results}

Table 5 shows an overview of all meta-analyses including the respective combined effects and measures of heterogeneity.

An overview of the average Std diff in means (change pre-to-post exercise) of stem and progenitor cell numbers at different times after exercise is provided in Fig. 6. Each datapoint represents the effect of exercise found for the respective cell population at the specified timepoint/-range and thus shows the resulting combined effect size of one individual meta-analysis. 
a

Reference

Statistics for each study

Std diff in means and $95 \% \mathrm{Cl}$

Adams et al., 2008

Bonisgnore et al., $2010(1.5 \mathrm{~km})$

Bonisgnore et al., 2010 (1.5km, CFU)

Goussetis et al., 2009

Krüger et al., 2015 (CET)

Krüger et al., 2015 (RET)

Krüger et al., 2015 (ECC)

Krüger et al., 2016 (CONT)

Krüger et al., 2016 (HIIT)

Lansford et al., $2016(\mathrm{~m})$

Lansford et al., 2016 (f)

Möbius-Winkler \& Hilberg et al., 2009

Montgomery et al., 2019

Niemiro et al., 2018
Niemiro et al., 2017

O'Caroll et al., 2019 (CONTEX)

O'Caroll et al., 2019 (SPRINT)

Obeid et al., 2015 (MICE)

Obeid et al., 2015 (HIIE)

Palange et al., 2006

Ribeiro et al., 2017 (60\%)

Ribeiro et al., 2017 (70\%)

Ribeiro et al., $2017(80 \%)$

Ross et al., 2017 (young)

Ross et al., 2017 (old)

Rummens et al., 2012

Sapp et al., 2019 (MOD)

Sapp et al., 2019 (HII)

Shill et al., $2016(\mathrm{~m})$

Shill et al., 2016 (f)

Stelzer et al., 2015

Strömberg et al., 2017

Wang et al., 2014 (group HT)

Wang et al., 2014 (group NT)

Std diff Standard

in means error $p$-Value

$\begin{array}{lll}0.16 & 0.11 & 0.153\end{array}$

$\begin{array}{lll}1.19 & 0.58 & 0.042\end{array}$

$\begin{array}{lll}0.84 & 0.52 & 0.107\end{array}$

$\begin{array}{lll}4.81 & 1.00 & 0.000\end{array}$

$\begin{array}{lll}0.57 & 0.28 & 0.040\end{array}$

$\begin{array}{lll}0.56 & 0.28 & 0.043 \\ 0.78 & 0.29 & 0.008\end{array}$

$\begin{array}{lll}0.92 & 0.32 & 0.004\end{array}$

$\begin{array}{lll}0.48 & 0.27 & 0.081\end{array}$

$\begin{array}{lll}0.36 & 0.23 & 0.119\end{array}$

$\begin{array}{lll}-0.10 & 0.28 & 0.723\end{array}$

$\begin{array}{lll}1.37 & 0.29 & 0.000\end{array}$

$\begin{array}{lll}1.26 & 0.40 & 0.002\end{array}$

$\begin{array}{lll}0.64 & 0.37 & 0.086\end{array}$

$\begin{array}{lll}0.44 & 0.33 & 0.182\end{array}$

$\begin{array}{lll}0.33 & 0.38 & 0.374\end{array}$

$\begin{array}{lll}0.54 & 0.39 & 0.170 \\ 1.57 & 0.77 & 0.042\end{array}$

$\begin{array}{lll}1.57 & 0.77 & 0.042 \\ 0.89 & 0.75 & 0.235\end{array}$

$\begin{array}{lll}0.89 & 0.75 & 0.235 \\ 0.11 & 0.26 & 0.672\end{array}$

$\begin{array}{lll}0.50 & 0.26 & 0.058\end{array}$

$\begin{array}{lll}1.31 & 0.35 & 0.000\end{array}$

$\begin{array}{lll}2.19 & 0.46 & 0.000\end{array}$

$\begin{array}{lll}0.93 & 0.38 & 0.014\end{array}$

$\begin{array}{lll}1.04 & 0.37 & 0.005\end{array}$

$\begin{array}{lll}0.09 & 0.18 & 0.615\end{array}$

$\begin{array}{lll}-0.97 & 0.54 & 0.074\end{array}$

$\begin{array}{lll}-0.59 & 0.43 & 0.171\end{array}$

$\begin{array}{lll}0.42 & 0.28 & 0.136 \\ 1.37 & 0.37 & 0.000\end{array}$

$\begin{array}{lll}-0.86 & 0.37 & 0.000\end{array}$

$\begin{array}{ccc}-0.86 & 0.40 & 0.029 \\ 0.57 & 0.31 & 0.060\end{array}$

$\begin{array}{lll}0.57 & 0.31 & 0.060\end{array}$

$\begin{array}{lll}1.07 & 0.25 & 0.000\end{array}$

$\begin{array}{lll}0.66 & 0.11 & 0.000\end{array}$

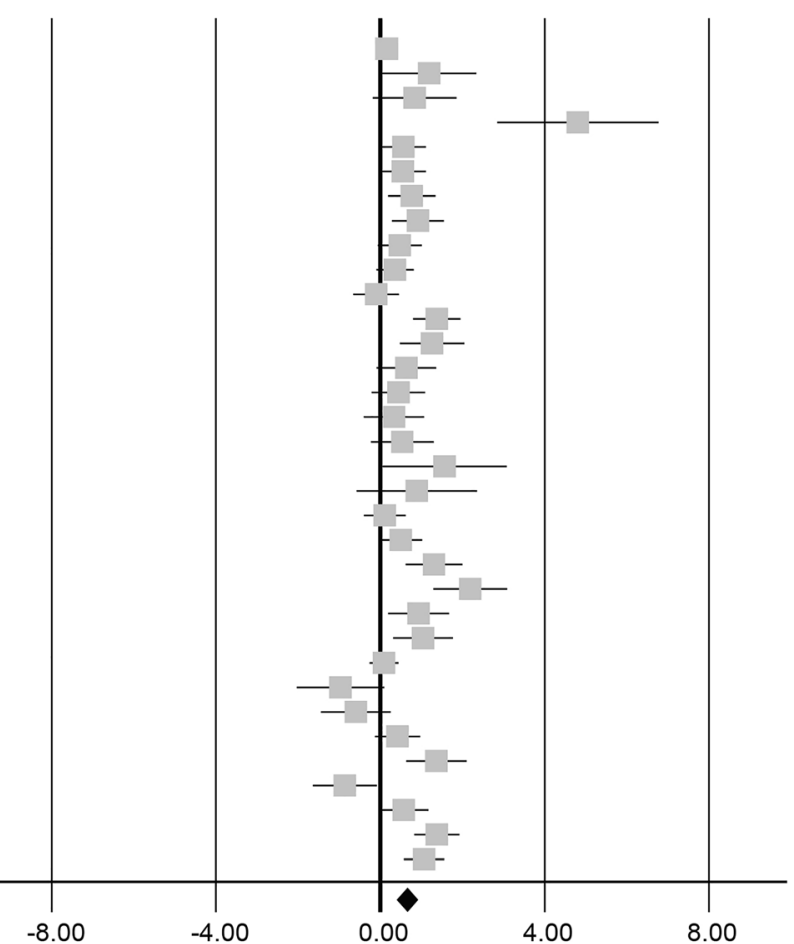

b

Reference

Statistics for each study

Std diff in means and $95 \% \mathrm{CI}$

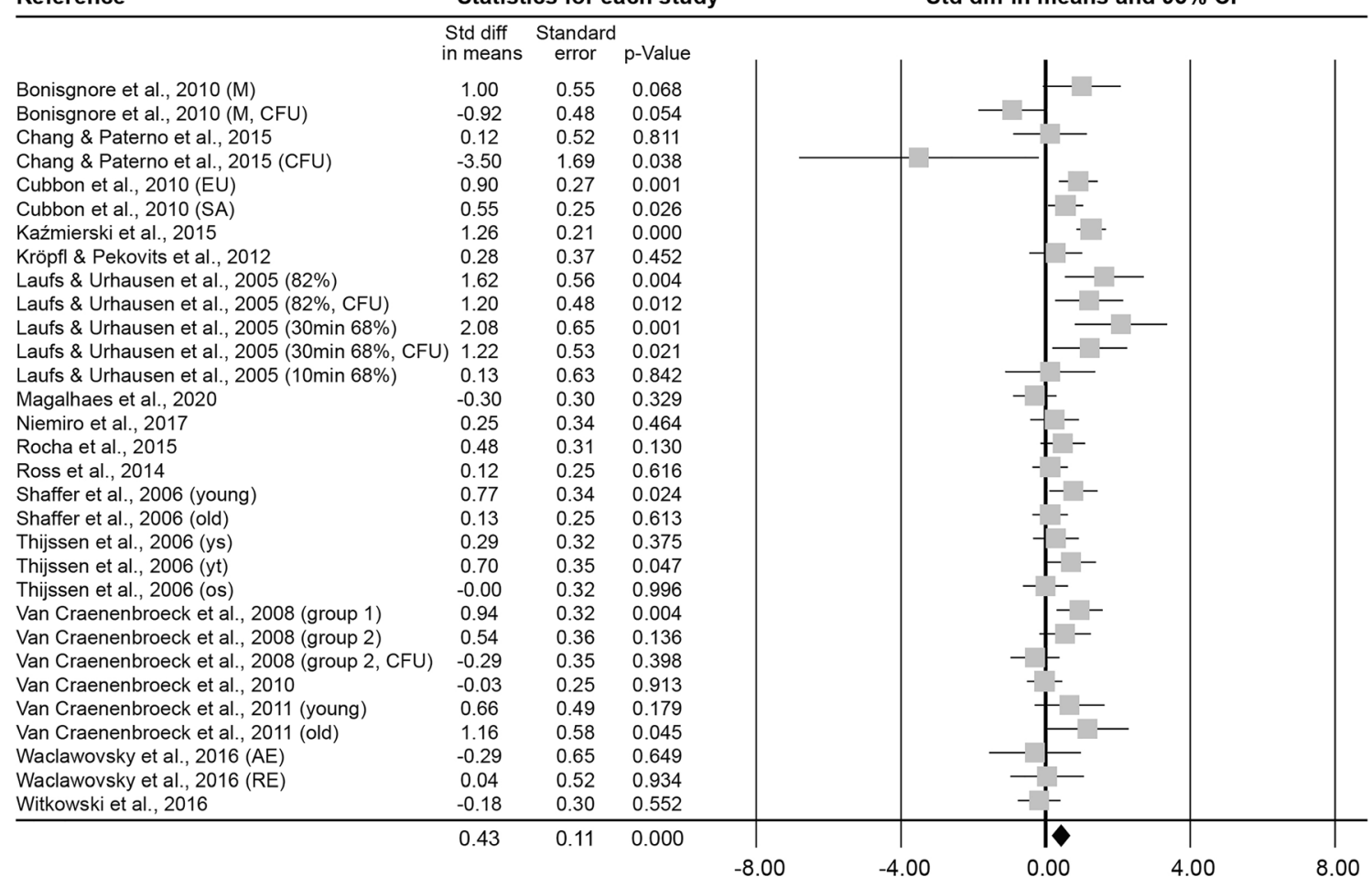

Fig. 3 Forest plot of ESCs $0-5 \mathrm{~min}(\mathbf{a}), 6-20 \mathrm{~min}(\mathbf{b}), 0.5 \mathrm{~h}(\mathbf{c}), 1 \mathrm{~h}(\mathbf{d}), 2 \mathrm{~h}(\mathbf{e}), 3-8 \mathrm{~h}(\mathbf{f})$ and $12-48 \mathrm{~h}$ post-exercise $(\mathbf{g})$. Std diff $=$ standardized difference, $\mathrm{CI}=$ confidence interval 
C

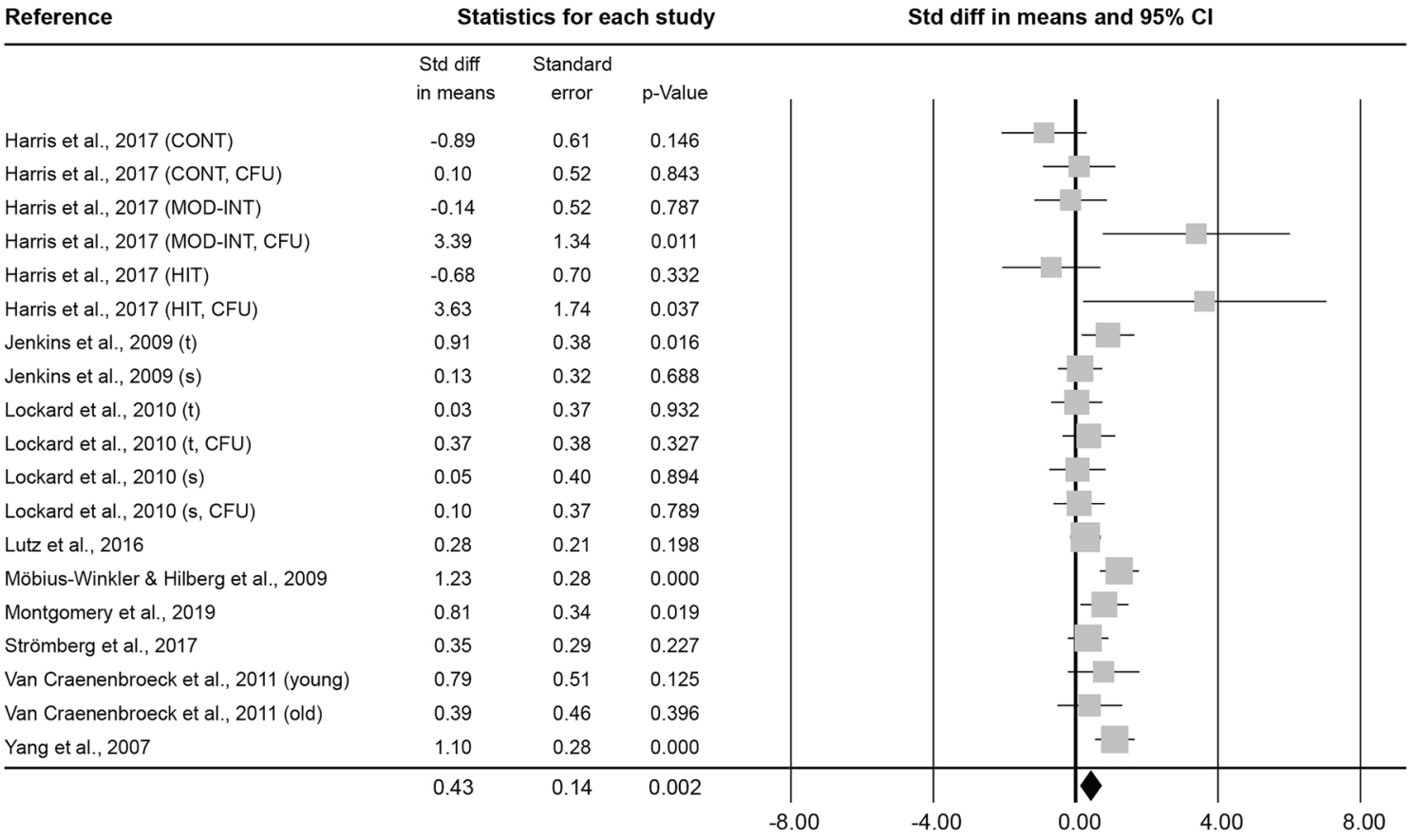

d

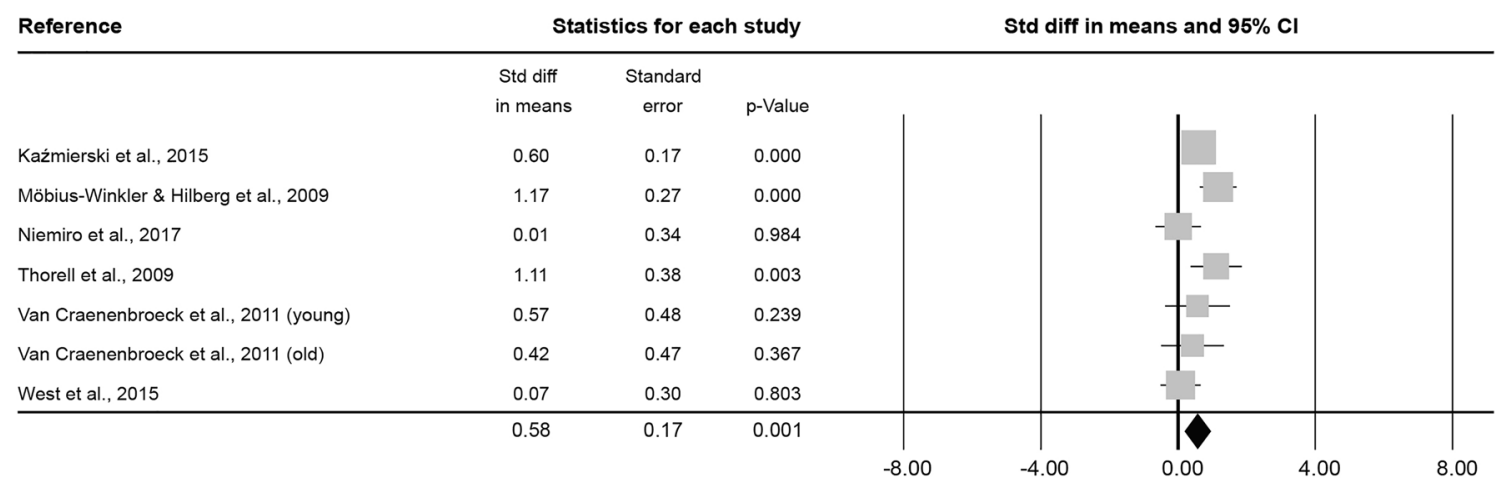

e

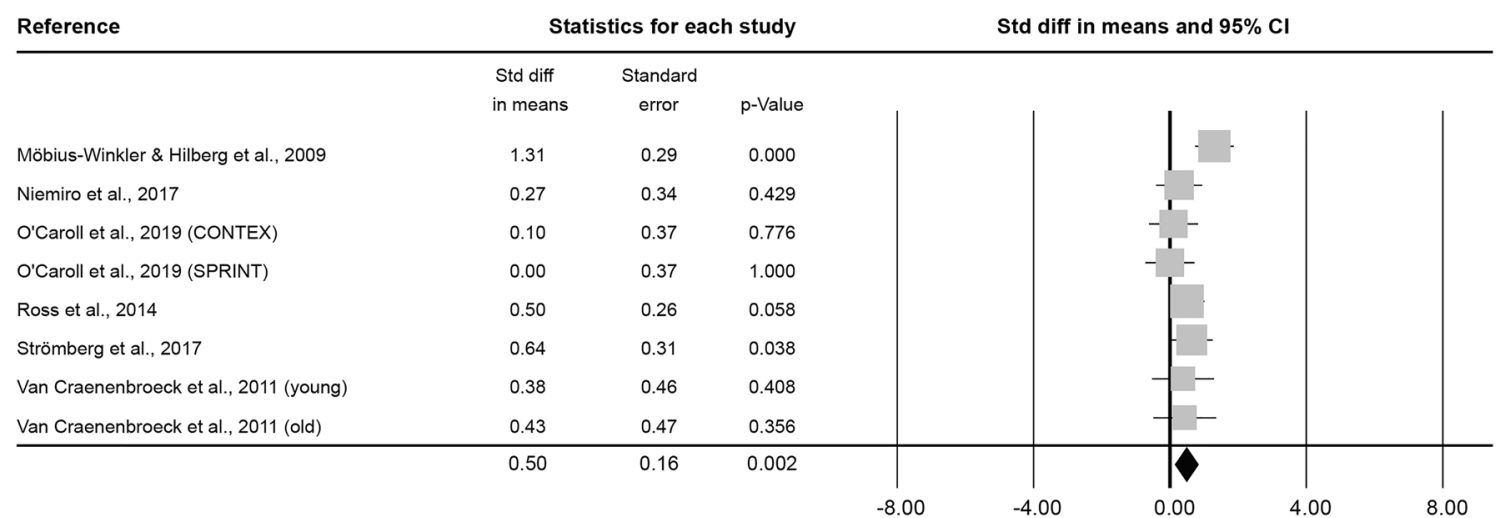

Fig. 3 (continued)

Assuming baseline values of $0.1-6.0 \%$ mononuclear blood cells (MNCs) with a maximal SD of $\pm 0.2 \%$ for
EPCs and $0.010-0.2 \% \mathrm{MNCs} \pm \max 0.01 \%$ for HSCs [85], and using formulas $2-4$, the obtained Std diff in 
f

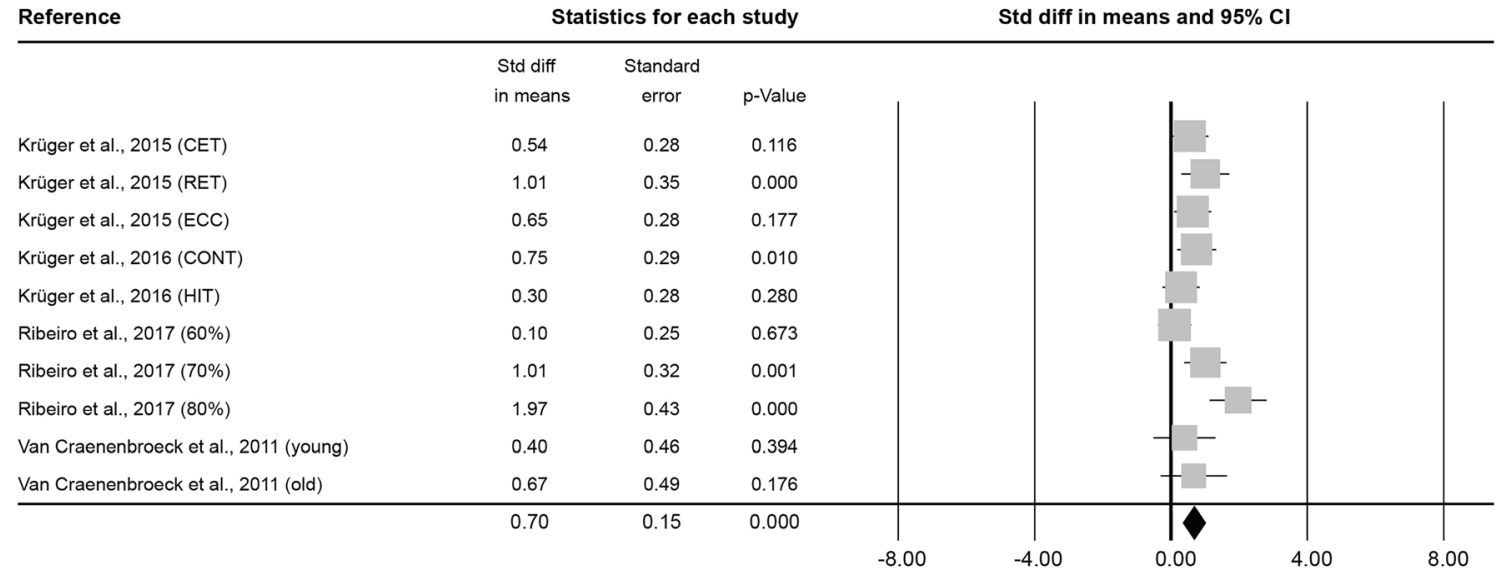

g

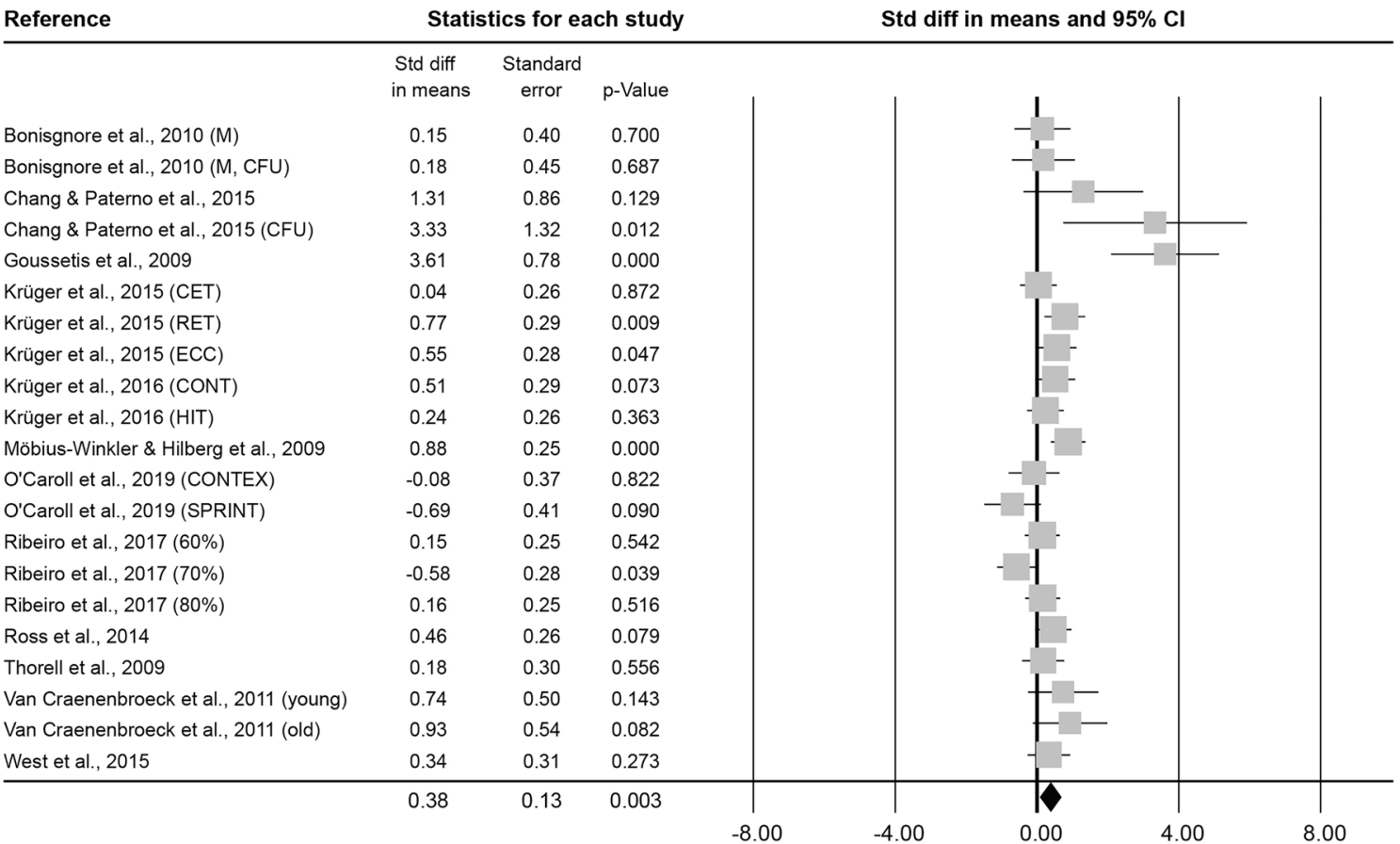

Fig. 3 (continued)

means of 0.66 for ESCs and 0.47 for HSCs, reflecting the true effects of exercise on stem cell mobilization directly after exercise, represent an increase of $0.15 \%$ and $0.005 \%$ MNCs, respectively. Assuming an estimate of approximately $2 \times 10^{6} \mathrm{MNCs} / \mathrm{ml}$ blood [86], this equals an absolute increase of 3000 cells $/ \mathrm{ml}$ for ESCs and 100 cells $/ \mathrm{ml}$ for HSCs.

\section{Risk of Bias across Studies}

The following five outcomes included 20 or more effect sizes and were thus analyzed for publication bias:

\section{Early and non-specified Stem and Progenitor Cells (enSCs), 0-5 min post}

Even though the funnel plot did not look noticeably asymmetric, Egger's regression test resulted in a significant $p$ - value of 0.000 . This was, however, not confirmed by the rank correlation test (Kendall's tau $=0.09$, $p=0.252$ ). Orwin's Fail - safe $N$ showed that 167 additional studies with an effect size of 0.0 would need to be added in order to render the cumulative effect size trivial $(\leq 0.05)$. The trim and fill method suggested that 5 studies reporting negative changes in cell numbers 
a

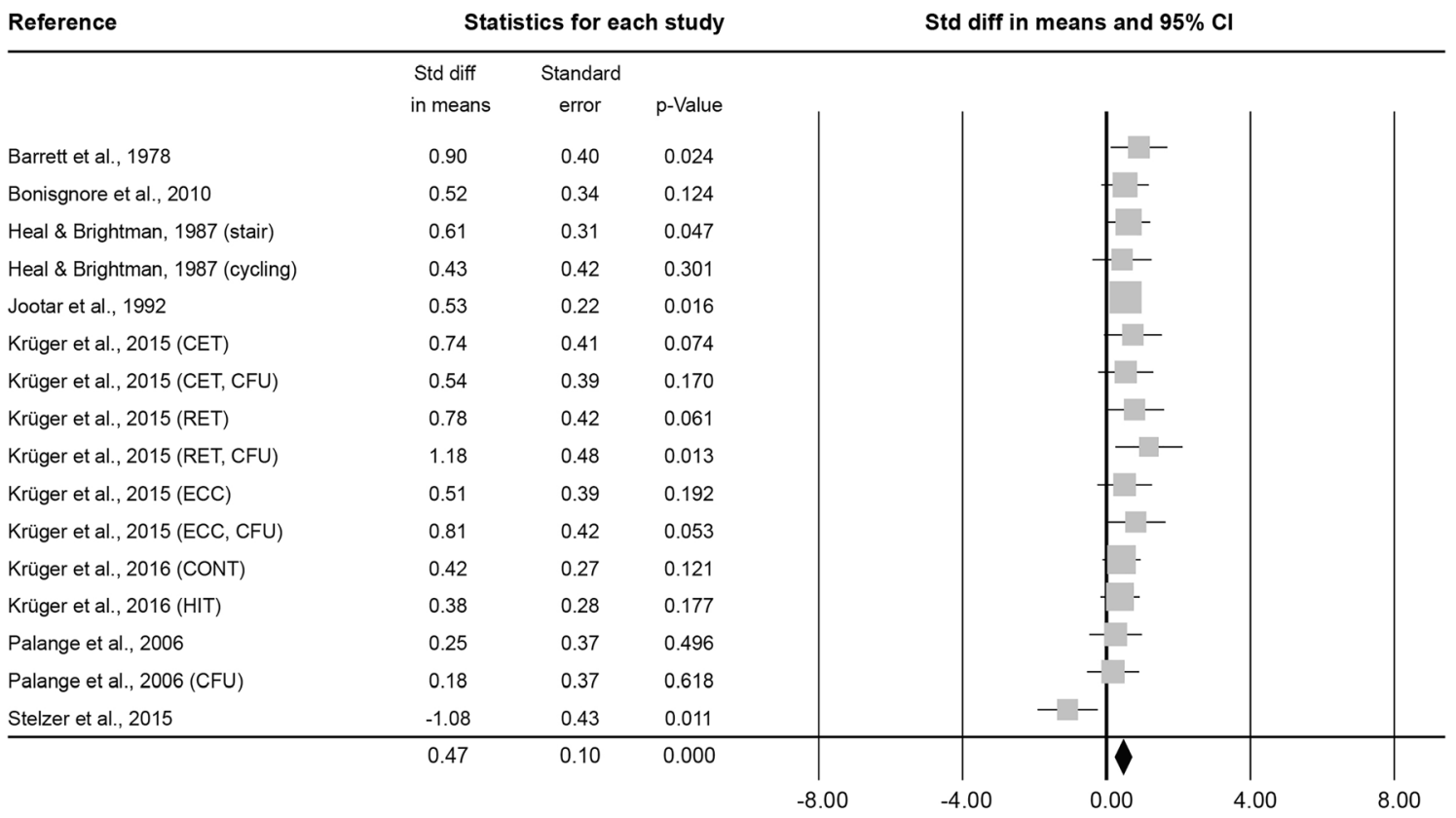

b

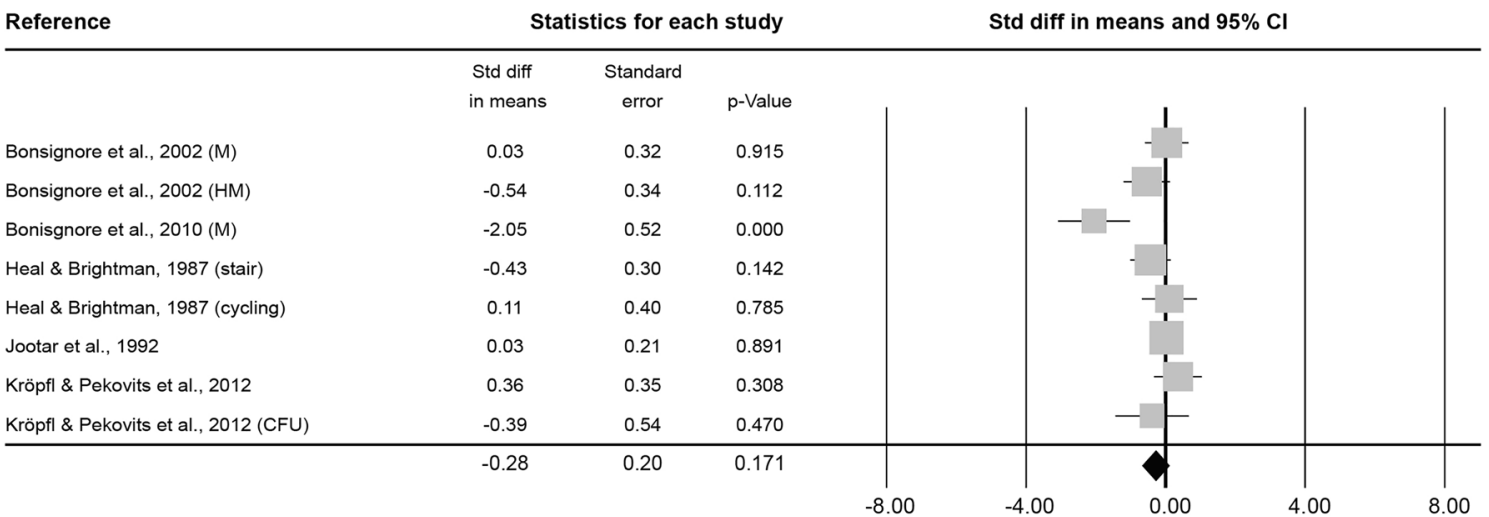

Fig. 4 Forest plot of HSCs $0-5 \min (\mathbf{a}), 6-20 \mathrm{~min}(\mathbf{b}), 0.5 \mathrm{~h} \mathrm{(c),} 1 \mathrm{~h}(\mathbf{d}), 3 \mathrm{~h}(\mathbf{e})$ and $12-24 \mathrm{~h}$ post-exercise $(\mathbf{f})$. Std diff $=$ standardized difference, CI $=$ confidence interval

were missing, and that their inclusion might change the effect size $(95 \% \mathrm{CI})$ of $0.64(0.32-0.97)$ to a computed effect of $0.53(0.22-0.84)$.

\section{Early and non-specified Stem and Progenitor Cells (enSCs), 6-20 min post}

Egger's test resulted in a significant $p$ - value $(p=0.031)$, while the rank correlation test failed to show a significant correlation between the inversed SE and the effect size (Kendall's tau $=0.19, p=0.080$ ). An additional 160 studies were predicted by Orwin's Fail - safe $N$ to be necessary to render the combined effect size trivial $(\leq 0.05)$. The inclusion of 3 missing studies to the left of the mean were suggested by the trim and fill test which would change the effect size from $0.42(0.19-0.64)$ to $0.30(0.07-0.54)$.

\section{Endothelial Stem and Progenitor Cells (ESCs), 0-5 min post}

Asymmetry of the funnel plot was confirmed by both, Egger's test $(p=0.004)$ and the rank correlation test (Kendall's tau $=$ $0.23, p=0.027)$. Orwin's Fail - safe $N$ suggested that the inclusion of an additional 313 studies with an effect size of 0.0 point estimates is needed to render the overall effect size insignificant $(\leq 0.05)$. The trim and fill method calculated a number of 8 studies to be missing and computed a new effect size of $0.41(0.19-0.64)$ (compared to $0.66(0.45-0.87))$ if they were to be included. 
C

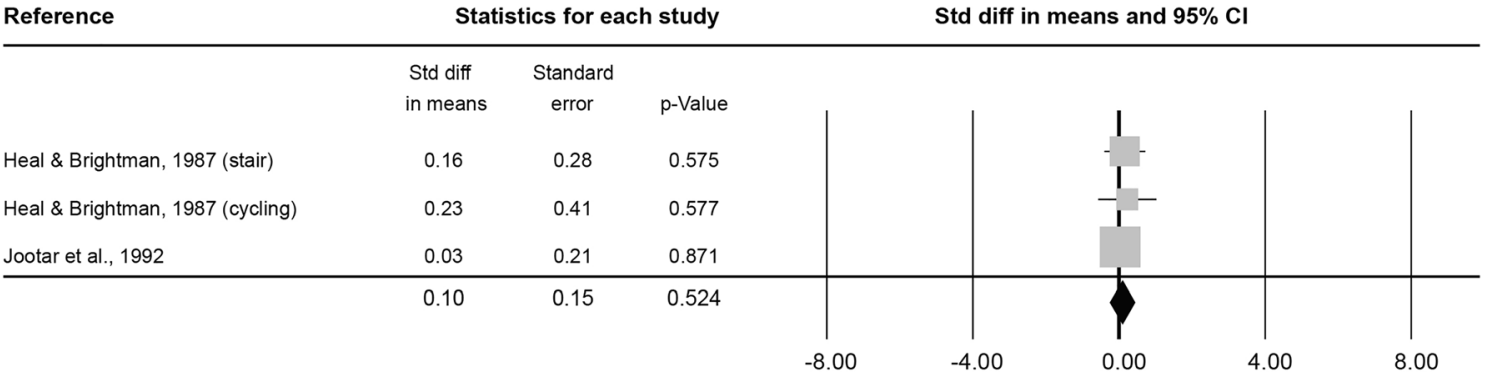

d

Reference $\quad$ Statistics for each study $\quad$ Std diff in means and $95 \% \mathrm{Cl}$

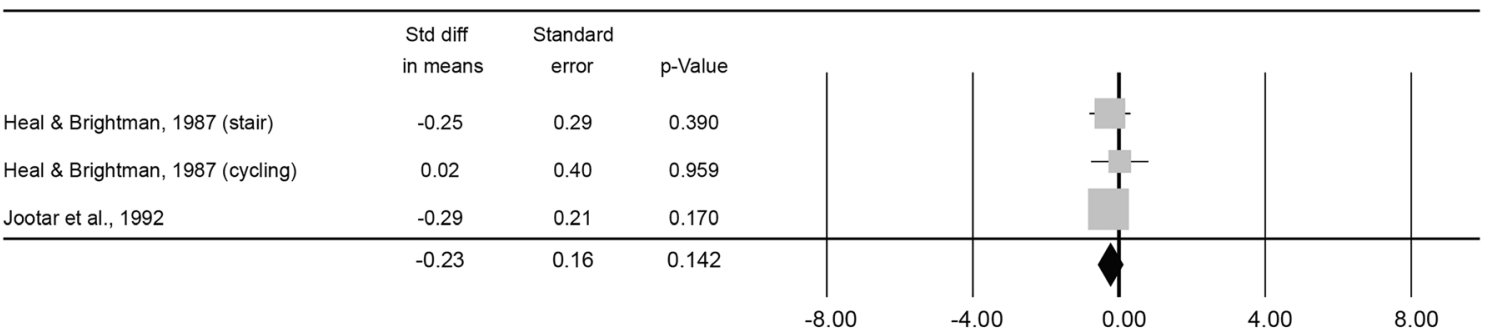

Fig. 4 (continued)

\section{Endothelial Stem and Progenitor Cells (ESCs), 6- $20 \mathrm{~min}$ post}

The funnel plot showed a very apparent symmetry, which was supported by both, Egger's regression test $(p=0.403)$ and the rank correlation test (Kendall's tau $=0.09, p=0.238$ ). Further, Orwin's Fail - safe $N$ yielded 234 studies would need to be added to render the effect size meaningless $(\leq 0.05)$ and the trim and fill method found 0 studies to be missing, leaving the effect size of $0.43(0.21-0.64)$ unchanged.

\section{Endothelial Stem and Progenitor Cells (ESCs), 12-48 h post}

The regression test resulted in a significant $p$ - value of 0.022 , indicating asymmetry in the funnel plot. This was however not confirmed by the rank correlation test (Kendall's tau $=0.25$, $p=0.055), .113$ studies were found by Orwin's Fail - safe $N$ and the trim and fill method suggested 3 additional studies to be included to the left of the mean, which would change the existing, significant effect size of $0.38(0.13-0.62)$ to a nonsignificant effect of $0.26(-0.01-0.55)$.

\section{Sensitivity analyses}

The following five outcomes included 20 or more effect sizes and were thus subjected to sensitivity analyses:

\section{Early and non-specified Stem and Progenitor Cells (enSCs), 0-5 min post}

The one-effect-size-removed analysis showed no change in significance of the combined Std diff in means $(p<0.001$ for all 27 effect sizes). Imputing a correlation coefficient of $r=0.5$ or $r=0.7$ instead of $r=0.6$, did not change the significance of the obtained effect size either $(0.5: 0.67 \pm 0.11$, $p<0.001 ; 0.7: 0.63 \pm 0.10, p<0.001)$.

\section{Early and non-specified Stem and Progenitor Cells (enSCs), 6-20 min post}

The removal of any of the 29 included effect sizes in the oneeffect-size-removed analysis did not change the significance of the combined Std diff in means. Similarly, the substitution of $r=0.6$ with $r=0.5$ or $r=0.7$ did not change the significance of the outcome $(0.5: 0.42 \pm 0.12, p<0.001 ; 0.7: 0.40 \pm 0.11$, $p<0.001)$.

\section{Endothelial Stem and Progenitor Cells (ESCs), 0-5 min post}

The one-effect-size-removed analysis showed no change in significance of the combined Std diff in means $(p<0.001$ for all 34 effect sizes)., neither did any applied adjustments to the correlation coefficient $(0.5: 0.68 \pm 0.11, p<0.001 ; 0.7$ : $0.63 \pm 0.10, p<0.001)$. 
e

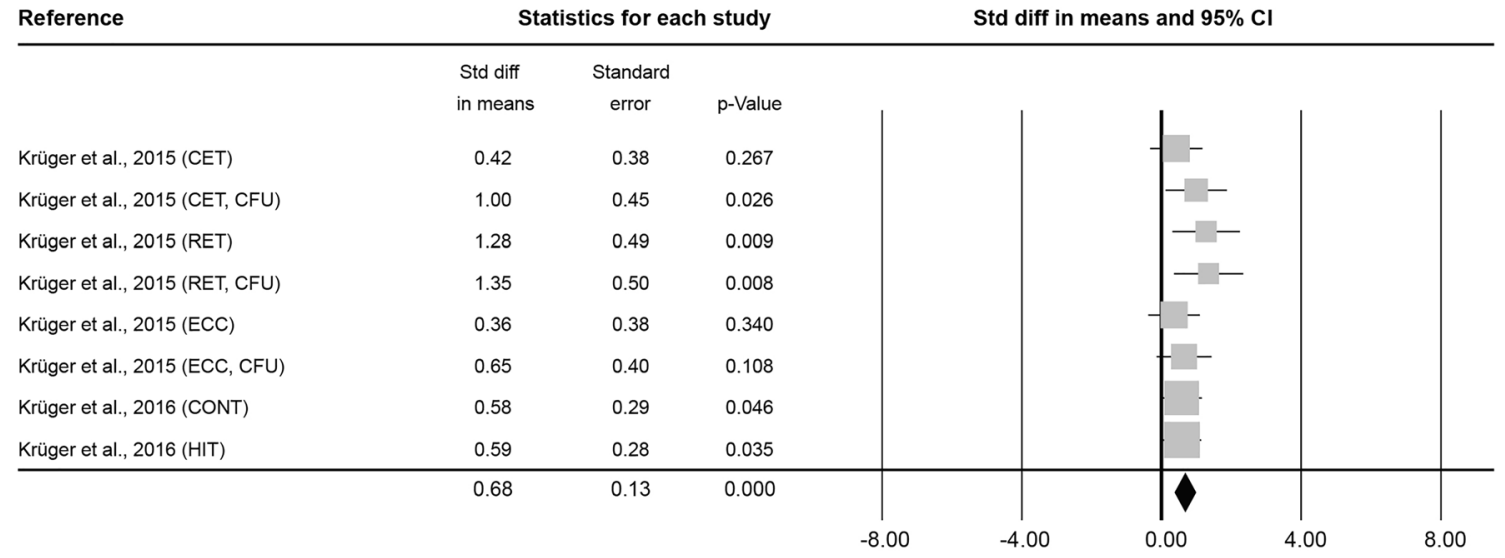

f

Reference

Statistics for each study

Std diff in means and $95 \% \mathrm{Cl}$

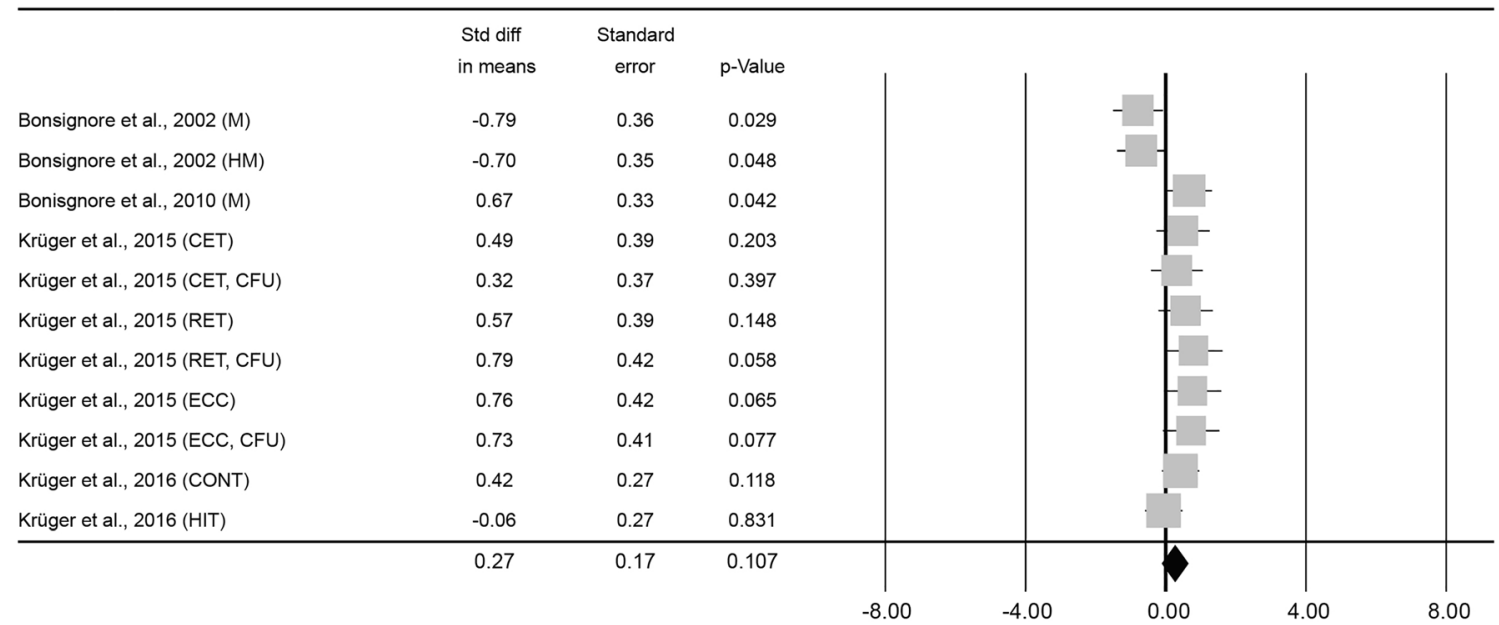

Fig. 4 (continued)

\section{Endothelial Stem and Progenitor Cells (ESCs), 6- $20 \mathrm{~min}$ post}

The originally obtained $p$-value of 0.000 did not change upon the application of the one-effect-size-removed analysis, no matter which one of the 31 included effect sizes was removed. Also adjusting $r$ from 0.6 to 0.5 or 0.7 did not result in any changes of the level of significance $(0.5: 0.44 \pm 0.11$, $p<0.001 ; 0.7: 0.41 \pm 0.11, p<0.001)$.

\section{Endothelial Stem and Progenitor Cells (ESCs), 12-48 h post}

The one-effect-size-removed analysis did not change the significance of the combined Std diff in means for any of the 21 effect sizes. Level of significance was also not substantially altered when imputing correlation coefficients of 0.5 or 0.7 (0.5: $0.37 \pm 0.13, p=0.004 ; 0.7: 0.37 \pm 0.12, p=0.002)$.

\section{Moderator variables}

All of the five outcomes including a minimum of 20 effect sizes also showed a significant heterogeneity of $I^{2}>50 \%$ in their results. They thus all qualified for further analysis of moderator variables via subgroup analysis and meta-regression. A detailed overview of the results is given in Table 6 .

\section{Early and non-specified Stem and Progenitor Cells (enSCs), 0-5 min post}

Meta-regressions revealed that none of the investigated moderator variables could significantly predict changes in enSCs measured between 0 and 5 min post-exercise compared to baseline (Sex: $p=0.700$, Age: $p=0.118$, BMI: $p=0.568$, Duration of the intervention: $p=0.199$, Total load of the intervention: $p=0.181$ ). Correcting for the variables removed $0 \%$ of the between-study variance, except for "age", which was responsible for $25 \%$ of the variance. 
a

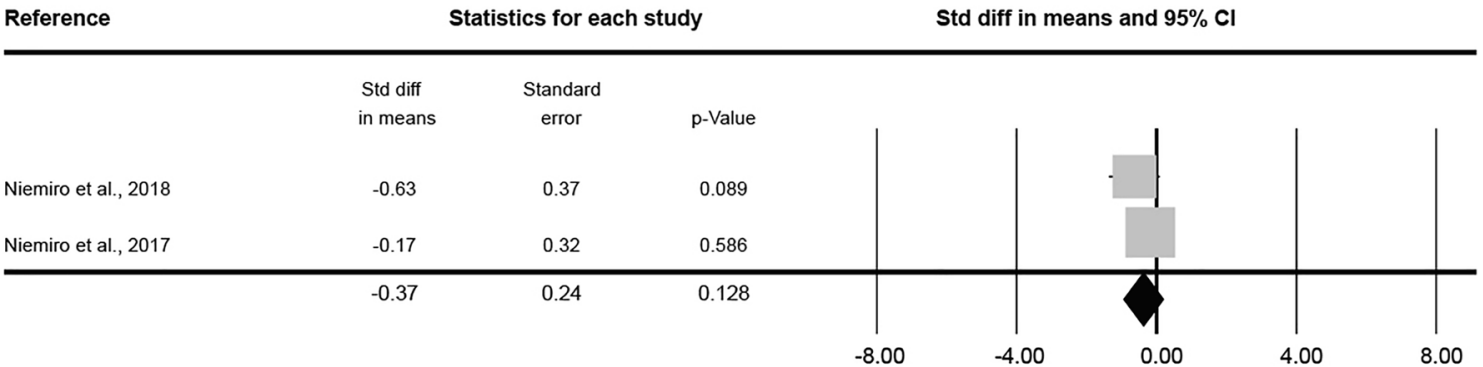

b

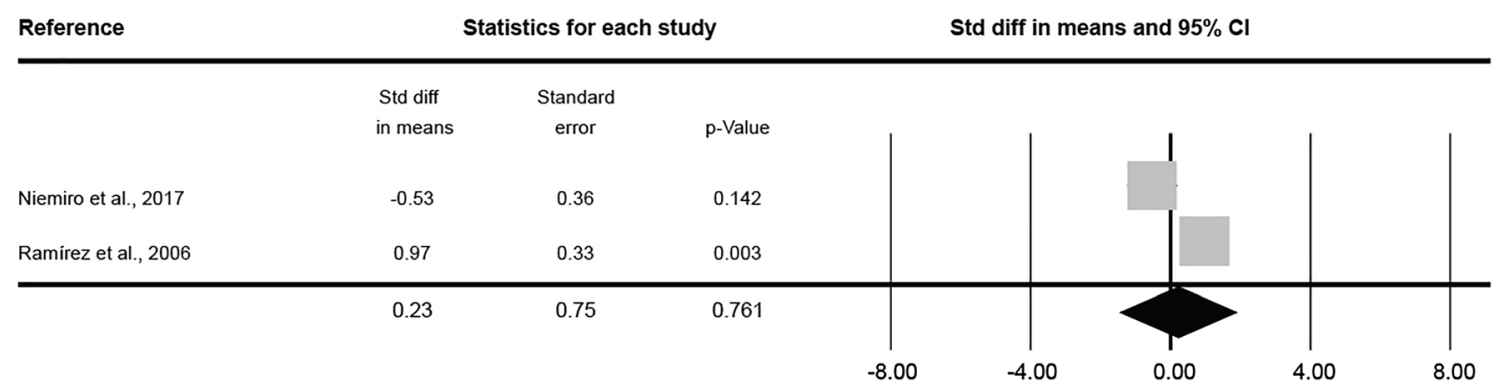

Fig. 5 Forest plot of MSCs $0-5 \min (\mathbf{a})$ and $2 \mathrm{~h}$ post-exercise (b). Std diff $=$ standardized difference, $\mathrm{CI}=$ confidence interval

Subgroup analyses categorizing effect sizes based on the intensity of the intervention, its modality or the baseline physical activity level of the subjects revealed that none of the categories within a subgroup differed significantly in their outcomes (Intensity: $p=0.947$, Modality: $p=0.485$, Baseline physical activity level: $p=0.244$ ).

\section{Early and non-specified Stem and Progenitor Cells (enSCs), 6-20 min post}

Meta-regressions revealed that none of the investigated moderator variables could significantly predict changes in enSCs measured between 6 and 20 min post-exercise compared to baseline (Sex: $p=0.957$, Age: $p=0.210$, BMI: $p=0.224$, Duration of the intervention: $p=0.112$, Total load of the intervention: $p=0.168$ ). Correcting for the variables removed $0 \%$ of the between-study variance, except for "age", which was responsible for $5 \%$ of the variance.

Subgroup analyses categorizing effect sizes based on the intensity of the intervention, its modality or the baseline physical activity level of the subjects revealed that none of the categories within a subgroup differed significantly in their outcomes (Intensity: $p=0.451$, Modality: $p=0.229$, Baseline physical activity level: $p=0.469$ ).

\section{Endothelial Stem and Progenitor Cells (ESCs), 0-5 min post}

Neither of the subject- or intervention-defining parameters significantly correlated with the changes in ESCs directly after exercise, as computed via meta-regressions (Sex: $p=0.390$ Age: $p=0.238$, BMI: $p=0.088$, Duration: $p=0.887$, Load: $p=0.845$ ).

Also, when divided into subgroups, none of the assessed parameters seemed to have a significant influence on the effect size (Intensity: $p=0.432$, Modality: $p=0.186$, Baseline physical activity level: $p=0.087$ ).

\section{Endothelial Stem and Progenitor Cells (ESCs), 6- $20 \mathrm{~min}$ post}

Similarly as for ESCs measured directly after exercise, changes in ESC numbers assessed between 6 and 20 min post were not significantly influenced by the percentage of males in the study cohort ( $p=0.886)$, subjects' mean age $(p=0.616)$ or their average BMI $(p=0.881)$. As for the intervention-defining parameters, neither the duration $(p=0.430)$, nor the load $(p=0.434)$ turned out to be significant predictor variables either.

Subgroup analysis showed a comparable picture: effect sizes for the three different intensity-groups ( $p=0.853)$, as well as for the groups representing the different exercise modalities $(p=$ 0.497), or for groups formed based on subjects' baseline physical activity level $(p=0.909)$ did not differ significantly.

\section{Endothelial Stem and Progenitor Cells (ESCs), 12-48 h post}

While age $(p=0.110)$ and BMI $(p=0.421)$ of the subject cohort were shown to not significantly correlate to the effect size, \%male subjects ( $p=0.010,46 \%$ variance explained), intervention duration $(p<0.001,59 \%$ variance explained) 
Table 5 Summary of combined effects and heterogeneity

\begin{tabular}{|c|c|c|c|c|c|c|c|c|c|}
\hline \multicolumn{2}{|l|}{ Outcome } & \multirow[t]{2}{*}{$\mathrm{N}$} & \multicolumn{3}{|c|}{ Combined effects } & \multicolumn{4}{|c|}{ Heterogeneity } \\
\hline Sub-group & Time bin & & $\begin{array}{l}\text { Std diff } \\
\text { in means }\end{array}$ & $95 \% \mathrm{CI}$ & $p$-value & $Q$-value & $d f(Q)$ & $p$-value & $I^{2}$ in $\%$ \\
\hline \multirow[t]{6}{*}{ enSCs } & $0-5 \min$ & 27 & 0.64 & $0.32-0.97$ & 0.000 & 197.0 & 26 & 0.000 & 86.8 \\
\hline & $6-20 \mathrm{~min}$ & 29 & 0.42 & $0.19-0.64$ & 0.000 & 95.1 & 28 & 0.000 & 70.6 \\
\hline & $0.5 \mathrm{~h}$ & 12 & 0.29 & $0.00-0.57$ & 0.049 & 22.6 & 11 & 0.020 & 51.3 \\
\hline & $1 \mathrm{~h}$ & 10 & 0.55 & $-0.01-1.10$ & 0.053 & 45.4 & 9 & 0.000 & 80.2 \\
\hline & $2 \mathrm{~h}$ & 12 & 0.21 & $-0.12-0.54$ & 0.209 & 32.5 & 11 & 0.001 & 66.1 \\
\hline & $3-96 h$ & 12 & 0.06 & $-0.21-0.33$ & 0.682 & 22.0 & 11 & 0.024 & 50.1 \\
\hline \multirow[t]{7}{*}{ ESCs } & $0-5 \min$ & 34 & 0.66 & $0.45-0.87$ & 0.000 & 128.6 & 33 & 0.000 & 74.3 \\
\hline & $6-20 \mathrm{~min}$ & 31 & 0.43 & $0.21-0.64$ & 0.000 & 80.9 & 30 & 0.000 & 62.9 \\
\hline & $0.5 \mathrm{~h}$ & 19 & 0.43 & $0.16-0.70$ & 0.002 & 38.4 & 18 & 0.003 & 53.1 \\
\hline & $1 \mathrm{~h}$ & 7 & 0.58 & $0.24-0.92$ & 0.001 & 12.5 & 6 & 0.052 & 52.0 \\
\hline & $2 \mathrm{~h}$ & 8 & 0.50 & $0.19-0.81$ & 0.002 & 11.6 & 7 & 0.113 & 39.8 \\
\hline & $3-8 h$ & 10 & 0.70 & $0.40-0.99$ & 0.000 & 19.2 & 9 & 0.023 & 53.2 \\
\hline & $12-48 h$ & 21 & 0.38 & $0.13-0.62$ & 0.003 & 55.7 & 20 & 0.000 & 64.1 \\
\hline \multirow[t]{6}{*}{ HSCs } & $0-5 \min$ & 16 & 0.47 & $0.28-0.67$ & 0.000 & 19.8 & 15 & 0.181 & 24.1 \\
\hline & $6-20 \mathrm{~min}$ & 8 & -0.28 & $-0.67-0.12$ & 0.171 & 19.1 & 7 & 0.008 & 63.3 \\
\hline & $0.5 \mathrm{~h}$ & 3 & 0.10 & $-0.20-0.40$ & 0.524 & 0.2 & 2 & 0.884 & 0.0 \\
\hline & $1 \mathrm{~h}$ & 3 & -0.23 & $-0.53-0.08$ & 0.142 & 0.5 & 2 & 0.790 & 0.0 \\
\hline & $3 \mathrm{~h}$ & 8 & 0.68 & $0.42-0.94$ & 0.000 & 5.1 & 7 & 0.644 & 0.0 \\
\hline & $12-24 \mathrm{~h}$ & 11 & 0.27 & $-0.06-0.60$ & 0.107 & 24.5 & 10 & 0.006 & 59.1 \\
\hline \multirow[t]{2}{*}{ MSCs } & $0-5 \min$ & 2 & -0.37 & $-0.84-0.11$ & 0.128 & 0.9 & 1 & 0.351 & 0.0 \\
\hline & $2 \mathrm{~h}$ & 2 & 0.23 & $-1.24-1.70$ & 0.761 & 9.5 & 1 & 0.002 & 89.5 \\
\hline
\end{tabular}

Std diff $=$ standardized difference, $\mathrm{CI}=$ confidence interval $\mathrm{df}=$ degrees of freedom, $\mathrm{N}=$ number of effect sizes included . Significant $p$ - values for effect sizes are in bold

and load ( $p<0.001,54 \%$ variance explained) turned out to be significant predictor variables for the change in ESC numbers measured $12-48 \mathrm{~h}$ after exercise. They all positively correlated with the effect size.

The categorical variables however, did not influence the outcome to a significant extent (Intensity: $p=0.920$, Modality: $p=$ 0.206, Baseline physical activity level: $p=0.497$ ).

\section{Discussion}

\section{Main Outcomes}

Most of the overall exercise-induced changes in stem and progenitor cell numbers had a Std diff in means of around $0.20-0.70$, representing a small to medium effect size [87]. We computed the obtained Std diff in means of 0.66 for ESCs and 0.47 for HSCs, reflecting the true effects of exercise on stem cell mobilization directly after exercise to represent an absolute increase of 3000 cells $/ \mathrm{ml}$ for ESCs and 100 cells $/ \mathrm{ml}$ for HSCs. These numbers show that exercise alone cannot nearly serve as a replacement for granulocyte colony stimulating factor (G-CSF), the most commonly used agent in clinical stem cell mobilization [88], yields increases of around $1.2 \times 10^{5} \mathrm{CD} 34^{+}$-cells $/ \mathrm{ml}$ following 4 daily injections of $7.5-10.0 \mu \mathrm{g} / \mathrm{kg}$ bodyweight [89], i.e. approximately 100 1000 fold the increase produced by exercise. However, since G-CSF-induced stem cell mobilization fails to evoke sufficient responses in 5-30\% of people [90, 91] and is also associated with side-effects [92], physical exercise may be considered as a potential adjuvant in the process of clinical stem cell mobilization [18], potentially enhancing the effect and/or reducing side-effects.

\section{Early and non-specified Stem and Progenitor Cells (enSCs)}

The biggest increase in enSC numbers was found immediately after exercise, with the effect being reduced thereafter, and no longer significant from $1 \mathrm{~h}$ post-exercise on. It is disputable, however, whether the lack of significance for the increase $1 \mathrm{~h}$ post-exercise with a rather considerable effect size of 0.55 was 
Fig. 6 Graphical summary of the main outcomes. enSCs = early and non-specified stem and progenitor cells, ESCs = endothelial stem and progenitor cells, HSCs $=$ hematopoietic stem and progenitor cells, MSCs = mesenchymal stem and progenitor cells. Data is given as Std diff in means $\pm \mathrm{SE}$, with the size of each datapoint representing the number of included effect sizes in the respective meta-analysis. Significant effects are depicted by filled symbols and level of significance: $* p<0.050$, $* * p<0.010, * * * p<0.001$
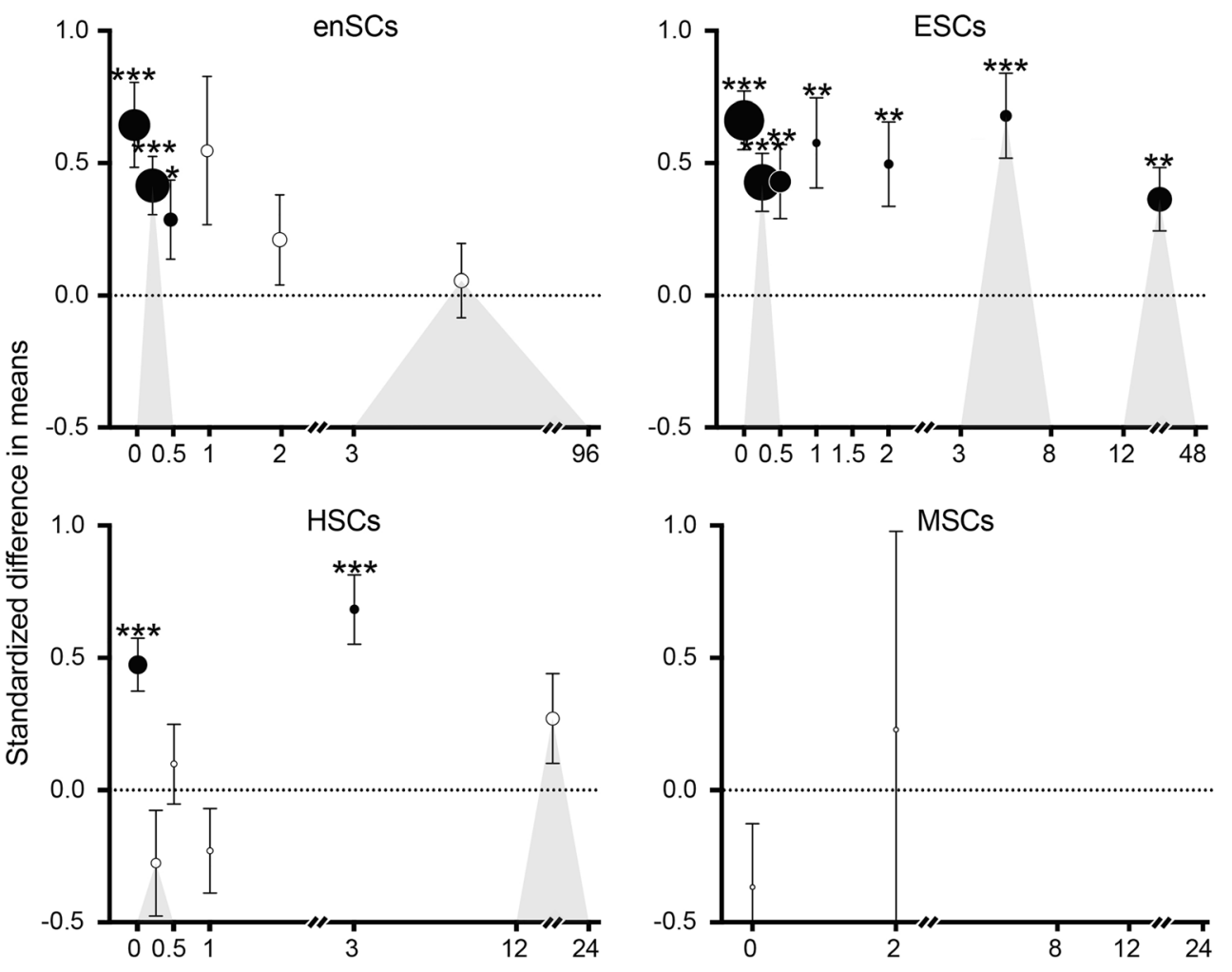

Time after exercise [h]

not solely due to the limited number of included outcomes $(n=10)$. In any case, SC numbers returned to baseline at least after $2 \mathrm{~h}$ of recovery. This recession of cell numbers might be explained by the homing of early stem cells into tissues throughout the body where they mediate repair responses or renew old cells [93].

\section{Endothelial Stem and Progenitor Cells (ESCs)}

Numbers of circulating ESCs increased directly after exercise cessation and remained elevated until $12 \mathrm{~h}$ post-exercise and beyond. Possibly, upon initial mobilization, ESCs remain in the blood stream for longer than HSCs or MSCs because their homing destination lies within the peripheral blood stream itself. The positive correlation between duration and load of exercise and the duration of ESC number elevation may suggest that recruitment of ESCs into the blood stream depends on the degree of strain that is applied to the vasculature.

\section{Hematopoietic Stem and Progenitor Cells (HSCs)}

The number of HSCs increased immediately after exercise but was back to baseline already $1 \mathrm{~min}$ later, a finding also reported in a previous review [18]. Although HSCs replenish the cells of the blood and therefore would not theoretically need to leave the blood stream, studies have found HSCs to home to distant tissues such as the heart [94], skeletal muscles [95] or the spleen [96]. They primarily migrate to sites of inflammation and damaged tissues to assist in their repair process [97] which could explain the fast drop in HSC numbers.

Interestingly, our results showed a second increase in HSC numbers $3 \mathrm{~h}$ post-exercise. This is in line with a finding by Mooren \& Krüger, 2015 [98] showing that apoptotic lymphocytes, intravenously injected into a mouse vein, lead to a dosedependent $\mathrm{Sca}-1^{+} / \mathrm{c}-\mathrm{kit}^{+}$progenitor cell mobilization $3 \mathrm{~h}$ after injection. As acute exercise has already been shown to induce lymphocyte apoptosis in circulation and tissue [99, 100], these authors hypothesized that (exercise-induced) apoptotic lymphocytes exert signaling functions relevant to HSCs. However, whether this link is directly applicable to the human system as well, possibly explaining this second increase in HSC number, remains to be evaluated separately.

\section{Mesenchymal Stem and Progenitor Cells (MSCs)}

Unfortunately, only three publications reported numbers of MSCs at 2 timepoints after acute exercise. This does not allow to draw meaningful conclusions regarding kinetics and extent of mobilization. However, results of these single studies look promising and the implication of MSCs not reacting to an acute bout of exercise with an increase in circulating numbers seen for ESCs and HSCs, warrants further investigation. 


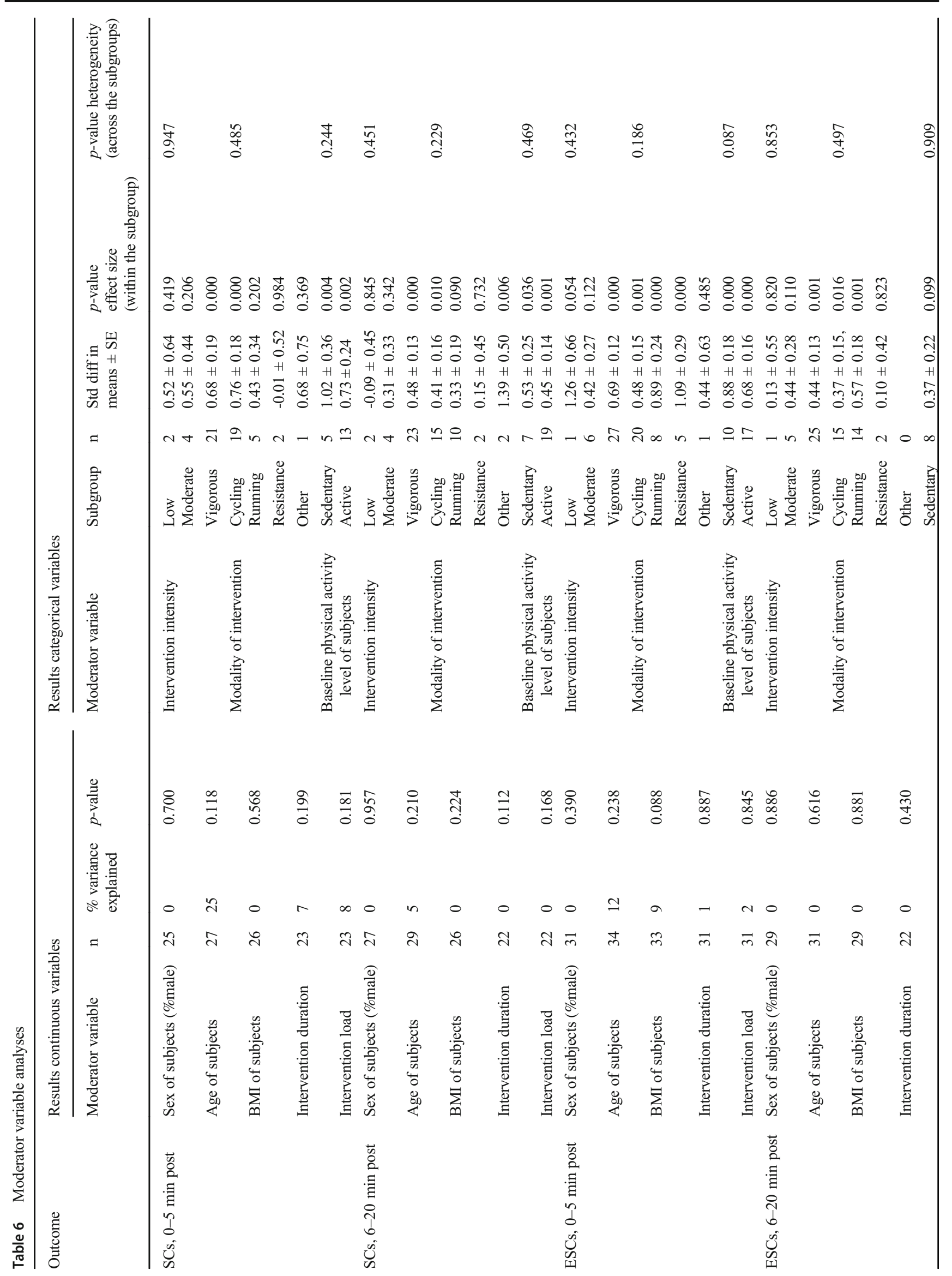


Despite very low concentrations in the peripheral blood (0.001- $0.100 \%$ of circulating MNCs [101]), MSCs represent an important and promising cell population, with a progeny able to differentiate into cells of the mesenchymal lineage, such as bone, cartilage, tendon, fat, and bone marrow stroma [101]. In the clinical context, these cells could support hematopoiesis and graft facilitation during cell transplantations or the treatment of various immune-related and degenerative diseases [102-104]. Furthermore, it has previously been shown in mice that repeated endurance exercise not only positively affects MSC quantity but also their quality in terms of differentiation potential [105], putting an even larger focus on exercise as a non-pharmacological tool for MSC mobilization. Establishing the true effect of exercise on MSC mobilization thus is of significant importance and therefore, future studies investigating exercise-dependent stem cell mobilization should also include measures of MSCs.

\section{Risk of Bias across Studies}

In order to assess the validity and applicability of the results, the risk of bias among the included studies was tested. The risk of bias within the conducted analysis is subsequently discussed for all qualified outcomes.

Based on visual inspection of the funnel plots and interpretation of the corresponding statistics, the impact of bias across studies was deemed trivial for data included in the meta-analysis of enSCs 0-5 min post-exercise. Studies reporting enSC numbers 6-20 min post-exercise were estimated to show a low degree of bias which, however, is considered to be insignificant to the presented outcome. In the case of ESC reporting, studies included in the meta-analysis 6-20 min post-exercise showed no indication of publication bias, while risk of bias across studies included in the meta-analyses $0-5$ min and $12-48 \mathrm{~h}$ post-exercise could not be excluded. However, in both cases, judging from the outcome of the Orwin's Fail - safe $N$ and the trim and fill method, the validity of our findings should not be called into question.

\section{Sensitivity Analyses}

To assure a combined result of multiple effect would not represent a single outcome of large magnitude affecting the overall effect in a disproportionate fashion, sensitivity analyses were conducted. For this, the combined effect size was calculated repeatedly, while sequentially excluding single effect sizes one by one.

Furthermore, data was tested for their robustness regarding the influence of the correlation coefficients which was imputed due to primary studies lacking the respective information.

In the present analysis, none of the computed outcomes that were subjected to sensitivity analyses showed significant changes by either test strategy which indicates high robustness of the obtained outcomes against disproportionate influences of individual studies. 


\section{Moderator Variables}

In the present analysis we could not confirm outcomes of single studies reporting differences in the mobilization of stem cells depending on subject-related variables such as age [10, $67,73]$ or training status $[40,46,53,60]$ nor on interventiondependent variables such as intensity [39, 41, 60, 61, 64, 69], or modality [49]. Only the number of ESCs $12-48 \mathrm{~h}$ after exercise was affected with larger effect sizes when percentage of male subjects was greater and when duration or load was higher. But given that only 6 out of 20 studies included females, and that the correlation to duration and load was lost when an ultra-marathon study was excluded [44], these relations may be questioned despite being significant. Certainly, an equal distribution of males and females should be achieved in future studies to clarify the influence of sex.

We thus conclude that the extent and the kinetics of the mobilization of stem and progenitor cells after exercise is susceptible to a variety of external and internal influences and moderators but none of them has a significant influence on its own. We therefore suggest that future studies standardize external influences as much as possible and report detailed information on subjects and their training status as well as all possible details of the interventions.

\section{Limitations}

As a first limitation we need to point out that grouping stem and progenitor cells into enSCs, ESCs, HSCs and MSCs proved to be more challenging than assumed since no consensus exists on the definition of marker combinations defining these cell populations, i.e. subgroups using the same nomenclature (e.g. "hematopoietic" or "endothelial" progenitor cells) in different studies include cells defined by different markers or marker combinations. For example, Thjissen et al., 2006 [73] and Baker et al., 2017 [39] define "hematopoietic stem cells" as CD34+, while Agha et al., 2018 [37], Bonsignore et al., 2010 [41] and Adams et al., 2008 [36] include $\mathrm{CD} 133^{+}$cells in addition to $\mathrm{CD} 34^{+}$in their definition of "hematopoietic stem and progenitor cells" and Niemiro et al., 2017 [59] refer to $\mathrm{CD} 34^{+}$cells more generally as "circulating progenitor cells" while defining "hematopoietic stem and progenitor cells" as $\mathrm{CD} 34^{+} / \mathrm{CD} 45^{\mathrm{dim}}$. This same definition problem was present also for endothelial and mesenchymal progenitors. Therefore, we decided to ignore the "group nomenclature" used in the original publications and instead extract the specific markers (or marker combinations) to identify cell subgroups. We are confident to thereby provide the best possible analysis of this data.

Second, studies contributing more than one effect size were corrected for by adjusting their individual weight, but the outcomes may still not be completely independent. This introduces a certain bias. However, an attempt for more detailed correction requires assumptions that may ultimately increase bias.
Third, the lack for correction for multiple testing may be perceived as a limitation. However, adjustment by the Bonferroni method [32], would have resulted in very large confidence intervals resulting in distorted representations of the true effect sizes. The statistical consultant therefore deemed the approach to be too conservative and not feasible in the present case.

Last, not all of the outcomes are equally well researched which limits the value of some of the analyses, e.g. for MSCs, where only 3 studies were available. However, we decided to still include all of the performed analyses in the study for the sake of completeness and to highlight weak points of present research, where further investigation is still needed.

\section{Conclusions}

Acute exercise elicits an increase in circulating stem and progenitor cell numbers but the significance and extent, as well as the kinetics of this mobilization vary markedly between the different subgroups of stem cells. ESC numbers are elevated until up to $48 \mathrm{~h}$ after exercise, while HSCs and enSCs transiently increase immediately after exercise, dropping back to baseline shortly after. However, more studies on exercise-induced mobilization of MSCs are required, as this cell subgroup represents a particularly promising target regarding stem cell transplantation and therapy and its non-invasive mobilization could provide a valuable asset in the clinical setting.

Since the identification of a cell as hematopoietic, endothelial or mesenchymal progenitor by cell-marker-combinations is employed very heterogeneously, a consensus regarding cell surface markers defining respective stem and progenitor cell subgroups is essential in order to improve clarity of mechanisms and communication in future research.

Acknowledgements The authors thank Chiara Vanetta (Statistical Consulting Service, ETH Zurich) for statistical counselling \& Dr. Jan Stutz (Exercise Physiology Lab, ETH Zurich) for general assistance and support.

Author Contributions MS, JMK and CMS conceived the study. MS performed the data search, selection, extraction and analyses. JMK performed data selection and extraction. MS, JMK and CMS interpreted the data, contributed to writing, and approved the final version of the manuscript.

Funding This research was funded by the ETH Zurich (Grant ETH43 15-2 to CMS and JMK).

Data Availability The datasets used and/or analyzed during the current study are available from the corresponding author on reasonable request.

\section{Compliance with Ethical Standards}

Consent for Publication Not applicable. 
Conflict of Interest The authors declare that they have no conflict of interest.

\section{Ethics Approval and Consent to Participate Not applicable.}

Abbreviations AE, Aerobic Exercise; CFU, Colony-Forming-Unit; enSCs, Early and non-specified Stem and Progenitor Cells; ESCs, Endothelial Stem and Progenitor Cells; EU, European; f, female; Fig., Figure; G-CSF, Granulocyte colony stimulating factor; HM, HalfMarathon; HSCs, Hematopoietic Stem and Progenitor Cells; HT, Hypoxic Training; LP, Late-Pubertal; M, Marathon; m, male; MeSH, Medical Subject Heading; MNCs, Mononuclear blood cells; MSCs, Mesenchymal Stem and Progenitor Cells; N or n, Number of Effect Sizes or Studies; NT, Normoxic Training; os, old sedentary; Paired diff, Paired mean difference; PRISMA, Preferred Reporting Items for Systematic Reviews and Meta-Analyses; r, Correlation Coefficient; RE, Resistance Exercise; s, sedentary; SA, South-Asian; SCs, Stem and Progenitor Cells; SD, Standard Deviation; SE, Standard Error; Std diff, Standardized difference; $t$, trained; ys, young sedentary; yt, young trained

Open Access This article is licensed under a Creative Commons Attribution 4.0 International License, which permits use, sharing, adaptation, distribution and reproduction in any medium or format, as long as you give appropriate credit to the original author(s) and the source, provide a link to the Creative Commons licence, and indicate if changes were made. The images or other third party material in this article are included in the article's Creative Commons licence, unless indicated otherwise in a credit line to the material. If material is not included in the article's Creative Commons licence and your intended use is not permitted by statutory regulation or exceeds the permitted use, you will need to obtain permission directly from the copyright holder. To view a copy of this licence, visit http://creativecommons.org/licenses/by/4.0/.

\section{References}

1. Ratajczak, M. Z., Liu, R., Marlicz, W., Blogowski, W., Starzynska, T., Wojakowski, W., \& Zuba-Surma, E. (2011). Identification of very small embryonic/epiblast-like stem cells (VSELs) circulating in peripheral blood during organ/tissue injuries. In Methods in Cell Biology (Vol. 103, pp. 31-54): Amsterdam: Elsevier.

2. Bhatia, M., Wang, J. C., Kapp, U., Bonnet, D., \& Dick, J. E. (1997). Purification of primitive human hematopoietic cells capable of repopulating immune-deficient mice. Proceedings of the National Academy of Sciences, 94(10), 5320-5325.

3. Asahara, T., Murohara, T., Sullivan, A., Silver, M., van der Zee, R., Li, T., Witzenbichler, B., Schatteman, G., \& Isner, J. M. (1997). Isolation of putative progenitor endothelial cells for angiogenesis. Science, 275(5302), 964-966.

4. Owen, M., \& Friedenstein, A. (1988). Stromal stem cells: marrow-derived osteogenic precursors. Paper presented at the Ciba Found Symp.

5. Goichberg, P. (2016). Current understanding of the pathways involved in adult stem and progenitor cell migration for tissue homeostasis and repair. Stem Cell Reviews and Reports, 12(4), 421437

6. Barrett, A. J., Longhurst, P., Sneath, P., \& Watson, J. G. (1978). Mobilization of CFU-C by exercise and ACTH induced stress in man. Experimental Hematology, 6(7), 590-594.
7. Heal, J. M., \& Brightman, A. (1987). Exercise and circulating hematopoietic progenitor cells (CFU-GM) in humans. Transfusion, 27(2), 155-158.

8. Jootar, S., Chaisiripoomkere, W., Thaikla, O., \& Kaewborworn, M. (1992). Effect of running exercise on hematological changes, hematopoietic progenitor cells (CFU-GM) and fibrinolytic system in humans. Journal of the Medical Association of Thailand, 75(2), 94-98.

9. Laufs, U., Urhausen, A., Werner, N., Scharhag, J., Heitz, A., Kissner, G., Bohm, M., Kindermann, W., \& Nickenig, G. (2005). Running exercise of different duration and intensity: effect on endothelial progenitor cells in healthy subjects. European Journal of Cardiovascular Prevention and Rehabilitation, 12(4), 407-414.

10. Shaffer, R. G., Greene, S., Arshi, A., Supple, G., Bantly, A., Moore, J. S., Parmacek, M. S., \& Mohler, E. R., III. (2006). Effect of acute exercise on endothelial progenitor cells in patients with peripheral arterial disease. Vascular Medicine, 11(4), 219226.

11. Ramírez, M., Lucia, A., Gómez-Gallego, F., Esteve-Lanao, J., Pérez-Martínez, A., Foster, C., Andreu, A. L., Martin, M. A., Madero, L., \& Arenas, J. (2006). Mobilisation of mesenchymal cells into blood in response to skeletal muscle injury. British Journal of Sports Medicinee, 40(8), 719-722.

12. Silva, J., Rocha, N. G., \& Nóbrega, A. (2012). Mobilization of endothelial progenitor cells with exercise in healthy individuals: a systematic review. Arquivos Brasileiros de Cardiologia, 98(2), 182-191.

13. Koutroumpi, M., Dimopoulos, S., Psarra, K., Kyprianou, T., \& Nanas, S. (2012). Circulating endothelial and progenitor cells: Evidence from acute and long-term exercise effects. World Journal of Cardiology, 4(12), 312.

14. Volaklis, K. A., Tokmakidis, S. P., \& Halle, M. (2013). Acute and chronic effects of exercise on circulating endothelial progenitor cells in healthy and diseased patients. Clinical Research in Cardiology, 102(4), 249-257.

15. De Biase, C., De Rosa, R., Luciano, R., De Luca, S., Capuano, E., Trimarco, B., \& Galasso, G. (2014). Effects of physical activity on endothelial progenitor cells (EPCs). Frontiers in Physiology, 4, 414.

16. De Lisio, M., \& Parise, G. (2013). Exercise and hematopoietic stem and progenitor cells: protection, quantity, and function. Exercise and Sport Sciences Reviews, 41(2), 116-122.

17. Boppart, M. D., De Lisio, M., \& Witkowski, S. (2015). Exercise and stem cells. In Progress in molecular biology and translational science (Vol. 135, pp. 423-456): Amsterdam: Elsevier.

18. Emmons, R., Niemiro, G. M., \& De Lisio, M. (2016). Exercise as an adjuvant therapy for hematopoietic stem cell mobilization. Stem Cells International, 2016(7), 1-11.

19. Moher, D., Liberati, A., Tetzlaff, J., Altman, D. G., \& Group, P. (2009). Preferred reporting items for systematic reviews and metaanalyses: the PRISMA statement. Annals of Internal Medicine, 151(4), 264-269.

20. Liberati, A., Altman, D. G., Tetzlaff, J., Mulrow, C., Gøtzsche, P. C., Ioannidis, J. P., Clarke, M., Devereaux, P. J., Kleijnen, J., \& Moher, D. (2009). The PRISMA statement for reporting systematic reviews and meta-analyses of studies that evaluate health care interventions: explanation and elaboration. Annals of Internal Medicine, 151(4), W-65-W-94.

21. Harris, J. D., Quatman, C. E., Manring, M., Siston, R. A., \& Flanigan, D. C. (2014). How to write a systematic review. The American Journal of Sports Medicine, 42(11), 2761-2768.

22. Huwaldt, J., \& Steinhorst, S. (2015). Plot digitizer software. Version 2.6.8. http://plotdigitizer.sourceforge.net/.

23. Moga, C., Guo, B., Schopflocher, D., \& Harstall, C. (2012). Development of a quality appraisal tool for case series studies 
using a modified Delphi technique. Edmonton: Institute of Health Economics.

24. Wan, X., Wang, W., Liu, J., \& Tong, T. (2014). Estimating the sample mean and standard deviation from the sample size, median, range and/or interquartile range. BMC Medical Research Methodology, 14, 135.

25. Garber, C. E., Blissmer, B., Deschenes, M. R., Franklin, B. A., Lamonte, M. J., Lee, I.-M., Nieman, D. C., \& Swain, D. P. (2011). Quantity and quality of exercise for developing and maintaining cardiorespiratory, musculoskeletal, and neuromotor fitness in apparently healthy adults: guidance for prescribing exercise. Medicine \& Science in Sports \& Exercise, 43(7), 1334-1359.

26. ACSM. (2013). American College of Sports Medicine's guidelines for exercise testing and prescription. Philadelphia: Lippincott Williams \& Wilkins.

27. Marti, B., Laukkanen, R., \& Held, T. (1999). Beurteilung der Ausdauer aufgrund der VO2max: Standards des BASPO. Schweizerische Zeitschrift für Sportmedizin und Sporttraumatologie, 47(4), 173-174.

28. Thomas, M. L. (1989). The leukocyte common antigen family. Annual Review of Immunology, 7(1), 339-369.

29. Schmidt-Lucke, C., Fichtlscherer, S., Aicher, A., Tschöpe, C., Schultheiss, H.-P., Zeiher, A. M., \& Dimmeler, S. (2010). Quantification of circulating endothelial progenitor cells using the modified ISHAGE protocol. PLoS One, 5(11), e13790.

30. Sidney, L. E., Branch, M. J., Dunphy, S. E., Dua, H. S., \& Hopkinson, A. (2014). Concise review: evidence for CD34 as a common marker for diverse progenitors. Stem Cells, 32(6), 1380 1389.

31. Li, Z. (2013). CD133: a stem cell biomarker and beyond. Experimental Hematology \& Oncology, 2(1), 17.

32. Borenstein, M., Hedges, L. V., Higgins, J. P., \& Rothstein, H. R. (2010). A basic introduction to fixed-effect and random-effects models for meta-analysis. Research Synthesis Methods, 1(2), 97-111.

33. Follmann, D., Elliott, P., Suh, I., \& Cutler, J. (1992). Variance imputation for overviews of clinical trials with continuous response. Journal of Clinical Epidemiology, 45(7), 769-773.

34. Rosenthal, R. (1986). Meta-analytic procedures for social science research Sage Publications: Beverly Hills, 1984, 148 pp. Educational Researcher, 15(8), 18-20.

35. Dickersin, K. (2005). Publication bias: Recognizing the problem, understanding its origins and scope, and preventing harm. Publication bias in meta-analysis: Prevention, assessment and adjustments, 11-33.

36. Adams, V., Linke, A., Breuckmann, F., Leineweber, K., Erbs, S., Krankel, N., Brocker-Preuss, M., Woitek, F., Erbel, R., Heusch, G., Hambrecht, R., Schuler, G., \& Mohlenkamp, S. (2008). Circulating progenitor cells decrease immediately after marathon race in advanced-age marathon runners. European Journal of Cardiovascular Prevention and Rehabilitation, 15(5), 602-607.

37. Agha, N. H., Baker, F. L., Kunz, H. E., Graff, R., Azadan, R., Dolan, C., Laughlin, M. S., Hosing, C., Markofski, M. M., Bond, R. A., Bollard, C. M., \& Simpson, R. J. (2018). Vigorous exercise mobilizes CD34 + hematopoietic stem cells to peripheral blood via the $\beta 2$-adrenergic receptor. Brain, Behavior, and Immunity, 68, 66-75.

38. Anz, A. W., Parsa, R. S., Romero-Creel, M. F., Nabors, A., Tucker, M. S., Harrison, R. M., \& Matuska, A. M. (2019). Exercise-mobilized platelet-rich plasma: short-term exercise increases stem cell and platelet concentrations in platelet-rich plasma. Arthroscopy - Journal of Arthroscopic and Related Surgery, 35(1), 192-200.

39. Baker, J. M., Nederveen, J. P., \& Parise, G. (2017). Aerobic exercise in humans mobilizes HSCs in an intensity-dependent manner. Journal of Applied Physiology (Bethesda, MD: 1985), 122(1), 182-190.

40. Bonsignore, M. R., Morici, G., Santoro, A., Pagano, M., Cascio, L., Bonanno, A., Abate, P., Mirabella, F., Profita, M., Insalaco, G., Gioia, M., Vignola, A. M., Majolino, I., Testa, U., \& Hogg, J. C. (2002). Circulating hematopoietic progenitor cells in runners. Journal of Applied Physiology (Bethesda, MD: 1985), 93(5), 1691-1697.

41. Bonsignore, M. R., Morici, G., Riccioni, R., Huertas, A., Petrucci, E., Veca, M., Mariani, G., Bonanno, A., Chimenti, L., Gioia, M., Palange, P., \& Testa, U. (2010). Hemopoietic and angiogenetic progenitors in healthy athletes: different responses to endurance and maximal exercise. Journal of Applied Physiology (Bethesda, MD: 1985), 109(1), 60-67.

42. Chang, E., Paterno, J., Duscher, D., Maan, Z. N., Chen, J. S., Januszyk, M., Rodrigues, M., Rennert, R. C., Bishop, S., Whitmore, A. J., Whittam, A. J., Longaker, M. T., \& Gurtner, G. C. (2015). Exercise induces stromal cell-derived factor-1 $\alpha$ mediated release of endothelial progenitor cells with increased vasculogenic function. Plastic and Reconstructive Surgery, 135(2), 340e-350e.

43. Cubbon, R. M., Murgatroyd, S. R., Ferguson, C., Bowen, T. S., Rakobowchuk, M., Baliga, V., Cannon, D., Rajwani, A., Abbas, A., Kahn, M., Birch, K. M., Porter, K. E., Wheatcroft, S. B., Rossiter, H. B., \& Kearney, M. T. (2010). Human exercise induced circulating progenitor cell mobilisation is nitric oxide dependent and is blunted in South Asian men. Heart, 96, A14.

44. Goussetis, E., Spiropoulos, A., Tsironi, M., Skenderi, K., Margeli, A., Graphakos, S., Baltopoulos, P., \& Papassotiriou, I. (2009). Spartathlon, a 246 kilometer foot race: Effects of acute inflammation induced by prolonged exercise on circulating progenitor reparative cells. Blood Cells, Molecules, and Diseases, 42(3), 294 299.

45. Harris, E., Rakobowchuk, M., \& Birch, K. M. (2017). Interval exercise increases angiogenic cell function in postmenopausal women. BMJ Open Sport \& Exercise Medicine, 3(1), e000248.

46. Jenkins, N. T., Witkowski, S., Spangenburg, E. E., \& Hagberg, J. M. (2009). Effects of acute and chronic endurance exercise on intracellular nitric oxide in putative endothelial progenitor cells: role of NAPDH oxidase. American Journal of Physiology. Heart and Circulatory Physiology, 297(5), H1798-H1805.

47. Kaźmierski, M., Wojakowski, W., Michalewska-Włudarczyk, A., Podolecka, E., Kotowski, M., Machaliński, B., \& Tendera, M. (2015). Exercise-induced mobilisation of endothelial progenitor cells in patients with premature coronary heart disease. Polish Heart Journal / Kardiologia Polska, 73(6), 411-418.

48. Kroepfl, J. M., Pekovits, K., Stelzer, I., Fuchs, R., Zelzer, S., Hofmann, P., Sedlmayr, P., Dohr, G., Wallner-Liebmann, S., Domej, W., \& Mueller, W. (2012). Exercise increases the frequency of circulating hematopoietic progenitor cells, but reduces hematopoietic colony-forming capacity. Stem Cells and Development, 21(16), 2915-2925.

49. Krüger, K., Pilat, C., Schild, M., Lindner, N., Frech, T., Muders, K., \& Mooren, F. C. (2015). Progenitor cell mobilization after exercise is related to systemic levels of G-CSF and muscle damage. Scandinavian Journal of Medicine \& Science in Sports, 25(3), e283-e291.

50. Krüger, K., Alack, K., Ringseis, R., Mink, L., Pfeifer, E., Schinle, M., Gindler, K., Kimmelmann, L., Walscheid, R., Muders, K., Frech, T., Eder, K., \& Mooren, F.-C. (2016). Apoptosis of TCell Subsets after Acute High-Intensity Interval Exercise. Medicine \& Science in Sports \& Exercise, 48(10), 2021-2029.

51. Lansford, K. A., Shill, D. D., Dicks, A. B., Marshburn, M. P., Southern, W. M., \& Jenkins, N. T. (2016). Effect of acute exercise on circulating angiogenic cell and microparticle populations. Experimental Physiology, 101(1), 155-167. 
52. Lee, H. S., Muthalib, M., Akimoto, T., \& Nosaka, K. (2015). Changes in the number of circulating CD34 + cells after eccentric exercise of the elbow flexors in relation to muscle damage. Journal of Sport and Health Science, 4(3), 275-281.

53. Lockard, M. M., Witkowski, S., Jenkins, N. T., Spangenburg, E. E., Obisesan, T. O., \& Hagberg, J. M. (2010). Thrombin and exercise similarly influence expression of cell cycle genes in cultured putative endothelial progenitor cells. Journal of Applied Physiology (Bethesda, MD: 1985), 108(6), 1682-1690.

54. Lutz, A. H., Blumenthal, J. B., Landers-Ramos, R. Q., \& Prior, S. J. (2016). Exercise-induced endothelial progenitor cell mobilization is attenuated in impaired glucose tolerance and type 2 diabetes. Journal of Applied Physiology (Bethesda, MD: 1985), 121(1), 36-41.

55. Magalhães, F. D. C., Aguiar, P. F., Tossige-Gomes, R., Magalhães, S. M., Ottone, V. D. O., Fernandes, T., Oliveira, E. M., Dias-Peixoto, M. F., Rocha-Vieira, E., \& Amorim, F. T. (2020). High-intensity interval training followed by postexercise cold-water immersion does not alter angiogenic circulating cells, but increases circulating endothelial cells. Applied Physiology, Nutrition, and Metabolism, 45(1), 101-111.

56. Möbius-Winkler, S., Hilberg, T., Menzel, K., Golla, E., Burman, A., Schuler, G., \& Adams, V. (2009). Time-dependent mobilization of circulating progenitor cells during strenuous exercise in healthy individuals. Journal of Applied Physiology (Bethesda, MD: 1985), 107(6), 1943-1950.

57. Montgomery, R., Paterson, A., Williamson, C., Florida-James, G., \& Ross, M. D. (2019). Blood flow restriction exercise attenuates the exercise-induced endothelial progenitor cells in healthy, young men. Frontiers in Physiology, 10, 447.

58. Morici, G., Zangla, D., Santoro, A., Pelosi, E., Petrucci, E., Gioia, M., Bonanno, A., Profita, M., Bellia, V., Testa, U., \& Bonsignore, M. R. (2005). Supramaximal exercise mobilizes hematopoietic progenitors and reticulocytes in athletes. American Journal of Physiology. Regulatory, Integrative and Comparative Physiology, 289(5), R1496-R1503.

59. Niemiro, G. M., Parel, J., Beals, J., van Vliet, S., Paluska, S. A., Moore, D. R., Burd, N. A., \& De Lisio, M. (2017). Kinetics of circulating progenitor cell mobilization during submaximal exercise. Journal of Applied Physiology (Bethesda, MD: 1985), 122(3), 675-682.

60. Niemiro, G. M., Edwards, T., Barfield, J. P., Beals, J. W., Broad, E. M., Motl, R. W., Burd, N. A., Pilutti, L. A., \& De Lisio, M. (2018). Circulating progenitor cell response to exercise in wheelchair racing athletes. Medicine \& Science in Sports \& Exercise, 50(1), 88-97.

61. O'Carroll, L., Wardrop, B., Murphy, R. P., Ross, M. D., \& Harrison, M. (2019). Circulating angiogenic cell response to sprint interval and continuous exercise. European Journal of Applied Physiology, 119(3), 743-752.

62. Obeid, J., Nguyen, T., Cellucci, T., Larche, M. J., \& Timmons, B. W. (2015). Effects of acute exercise on circulating endothelial and progenitor cells in children and adolescents with juvenile idiopathic arthritis and healthy controls: a pilot study. Pediatric Rheumatology Online Journal, 13(1), 41.

63. Palange, P., Testa, U., Huertas, A., Calabro, L., Antonucci, R., Petrucci, E., Pelosi, E., Pasquini, L., Satta, A., Morici, G., Vignola, M. A., \& Bonsignore, M. R. (2006). Circulating haemopoietic and endothelial progenitor cells are decreased in COPD. The European Respiratory Journal, 27(3), 529-541.

64. Ribeiro, F., Ribeiro, I. P., Goncalves, A. C., Alves, A. J., Melo, E., Fernandes, R., Costa, R., Sarmento-Ribeiro, A. B., Duarte, J. A., Carreira, I. M., Witkowski, S., \& Oliveira, J. (2017). Effects of resistance exercise on endothelial progenitor cell mobilization in women. Scientific Reports, 7(1), 17880.
65. Rocha, N. G., Sales, A. R., Penedo, L. A., Pereira, F. S., Silva, M. S., Miranda, R. L., Silva, J. F., Silva, B. M., Santos, A. A., \& Nobrega, A. C. (2015). Impaired circulating angiogenic cells mobilization and metalloproteinase- 9 activity after dynamic exercise in early metabolic syndrome. BioMed Research International, 2015, 920356.

66. Ross, M. D., Wekesa, A. L., Phelan, J. P., \& Harrison, M. (2014). Resistance exercise increases endothelial progenitor cells and angiogenic factors. Medicine \& Science in Sports \& Exercise, 46(1), $16-23$.

67. Ross, M. D., Malone, E. M., Simpson, R., Cranston, I., Ingram, L., Wright, G. P., Chambers, G., \& Florida-James, G. (2017). Lower resting and exercise-induced circulating angiogenic progenitors and angiogenic $\mathrm{T}$ cells in older men. American Journal of Physiology. Heart and Circulatory Physiology, 314(3), H392Hh402.

68. Rummens, J. L., Daniels, A., Dendale, P., Hensen, K., Hendrikx, M., Berger, J., Koninckx, R., \& Hansen, D. (2012). Suppressed increase in blood endothelial progenitor cell content as result of single exhaustive exercise bout in male revascularised coronary artery disease patients. Acta Clinica Belgica, 67(4), 262-269.

69. Sapp, R. M., Evans, W. S., Eagan, L. E., Chesney, C. A., Zietowski, E. M., Prior, S. J., Ranadive, S. M., \& Hagberg, J. M. (2019). The effects of moderate and high-intensity exercise on circulating markers of endothelial integrity and activation in young, healthy men. Journal of Applied Physiology, 127(5), 1245-1256.

70. Shill, D. D., Marshburn, M. P., Hempel, H. K., Lansford, K. A., \& Jenkins, N. T. (2016). Heterogeneous circulating angiogenic cell responses to acute maximal exercise. Medicine \& Science in Sports \& Exercise, 48(12), 2536-2543.

71. Stelzer, I., Kröpfl, J. M., Fuchs, R., Pekovits, K., Mangge, H., Raggam, R. B., Gruber, H. J., Prüller, F., Hofmann, P., Truschnig-Wilders, M., Obermayer-Pietsch, B., Haushofer, A. C., Kessler, H. H., \& Mächler, P. (2015). Ultra-endurance exercise induces stress and inflammation and affects circulating hematopoietic progenitor cell function. Scandinavian Journal of Medicine \& Science in Sports, 25(5), e442-e450.

72. Strömberg, A., Rullman, E., Jansson, E., \& Gustafsson, T. (2017). Exercise-induced upregulation of endothelial adhesion molecules in human skeletal muscle and number of circulating cells with remodeling properties. Journal of Applied Physiology (Bethesda, MD: 1985), 122(5), 1145-1154.

73. Thijssen, D. H., Vos, J. B., Verseyden, C., van Zonneveld, A. J., Smits, P., Sweep, F. C., Hopman, M. T., \& de Boer, H. C. (2006). Haematopoietic stem cells and endothelial progenitor cells in healthy men: effect of aging and training. Aging Cell, 5(6), 495 503.

74. Thorell, D., Borjesson, M., Larsson, P., Ulfhammer, E., Karlsson, L., \& DuttaRoy, S. (2009). Strenuous exercise increases late outgrowth endothelial cells in healthy subjects. European Journal of Applied Physiology, 107(4), 481-488.

75. Van Craenenbroeck, E. M., Vrints, C. J., Haine, S. E., Vermeulen, K., Goovaerts, I., Van Tendeloo, V. F., Hoymans, V. Y., \& Conraads, V. M. (2008). A maximal exercise bout increases the number of circulating CD34+/KDR + endothelial progenitor cells in healthy subjects. Relation with lipid profile. Journal of Applied Physiology (Bethesda, MD: 1985), 104(4), 1006-1013.

76. Van Craenenbroeck, E. M., Beckers, P. J., Possemiers, N. M., Wuyts, K., Frederix, G., Hoymans, V. Y., Wuyts, F., Paelinck, B. P., Vrints, C. J., \& Conraads, V. M. (2010). Exercise acutely reverses dysfunction of circulating angiogenic cells in chronic heart failure. European Heart Journal, 31(15), 1924-1934.

77. Van Craenenbroeck, E. M., Bruyndonckx, L., Van Berckelaer, C., Hoymans, V. Y., Vrints, C. J., \& Conraads, V. M. (2011). The effect of acute exercise on endothelial progenitor cells is 
attenuated in chronic heart failure. European Journal of Applied Physiology, 111(9), 2375-2379.

78. Waclawovsky, G., Umpierre, D., Figueira, F. R., De Lima, E. S., Alegretti, A. P., Schneider, L., Matte, U. S., Rodrigues, T. C., \& Schaan, B. D. (2016). Exercise on progenitor cells in healthy subjects and patients with type 1 diabetes. Medicine \& Science in Sports \& Exercise, 48(2), 190-199.

79. Wang, J.-S., Lee, M.-Y., Lien, H.-Y., \& Weng, T.-P. (2014). Hypoxic exercise training improves cardiac/muscular hemodynamics and is associated with modulated circulating progenitor cells in sedentary men. International Journal of Cardiology, 170(3), 315-323.

80. Wardyn, G. G., Rennard, S. I., Brusnahan, S. K., McGuire, T. R., Carlson, M. L., Smith, L. M., McGranaghan, S., \& Sharp, J. G. (2008). Effects of exercise on hematological parameters, circulating side population cells, and cytokines. Experimental Hematology, 36(2), 216-223.

81. West, D. J., Campbell, M. D., Gonzalez, J. T., Walker, M., Stevenson, E. J., Ahmed, F. W., Wijaya, S., Shaw, J. A., \& Weaver, J. U. (2015). The inflammation, vascular repair and injury responses to exercise in fit males with and without Type 1 diabetes: an observational study. Cardiovascular Diabetology, 14,71 .

82. Witkowski, S., Guhanarayan, G., \& Burgess, R. (2016). Glucose and acute exercise influence factors secreted by circulating angiogenic cells in vitro. Physiological Reports, 4(3), e12649.

83. Yang, Z., Wang, J. M., Chen, L., Luo, C. F., Tang, A. L., \& Tao, J. (2007). Acute exercise-induced nitric oxide production contributes to upregulation of circulating endothelial progenitor cells in healthy subjects. Journal of Human Hypertension, 21(6), 452460 .

84. Zaldivar, F., Eliakim, A., Radom-Aizik, S., Leu, S. Y., \& Cooper, D. M. (2007). The effect of brief exercise on circulating CD34 + stem cells in early and late pubertal boys. Pediatric Research, 61(4), 491-495.

85. Duda, D. G., Cohen, K. S., Scadden, D. T., \& Jain, R. K. (2007). A protocol for phenotypic detection and enumeration of circulating endothelial cells and circulating progenitor cells in human blood. Nature Protocols, 2(4), 805.

86. Kröpfl, J. M., Schmid, M., Di Marzio, Y., Schreiber, K., \& Spengler, C. M. (2019). Circulating adult stem and progenitor cell numbers - can results be trusted? Stem Cell Research \& Therapy, 10(1), 305.

87. Faraone, S. V. (2008). Interpreting estimates of treatment effects: implications for managed care. Pharmacy and Therapeutics, 33(12), 700.

88. Ghobadi, A., Fiala, M. A., Rettig, M., Schroeder, M., Uy, G. L., Stockerl-Goldstein, K., Westervelt, P., Vij, R., \& DiPersio, J. F. (2019). A phase I study of the safety and feasibility of bortezomib in combination with G-CSF for stem cell mobilization in patients with multiple myeloma. Clinical Lymphoma, Myeloma \& Leukemia, 19(10), e588-e593.

89. Stroncek, D., Clay, M., Herr, G., Smith, J., Jaszcz, W., Ilstrup, S., \& McCullough, J. (1997). The kinetics of G-CSF mobilization of CD34 + cells in healthy people. Transfusion Medicine, 7(1), 1924.

90. Rettig, M. P., Ansstas, G., \& DiPersio, J. F. (2012). Mobilization of hematopoietic stem and progenitor cells using inhibitors of CXCR4 and VLA-4. Leukemia, 26(1), 34-53.

91. Atilla, P. A., Ozturk, S. M. B., \& Demirer, T. (2017). How to manage poor mobilizers for high dose chemotherapy and autologous stem cell transplantation? Transfusion and Apheresis Science, 56(2), 190-198.
92. Tigue, C., McKoy, J., Evens, A., Trifilio, S., Tallman, M., \& Bennett, C. (2007). Granulocyte-colony stimulating factor administration to healthy individuals and persons with chronic neutropenia or cancer: an overview of safety considerations from the Research on Adverse Drug Events and Reports project. Bone Marrow Transplantation, 40(3), 185-192.

93. Marycz, K., Mierzejewska, K., Śmieszek, A., Suszynska, E., Malicka, I., Kucia, M., \& Ratajczak, M. Z. (2016). Endurance exercise mobilizes developmentally early stem cells into peripheral blood and increases their number in bone marrow: implications for tissue regeneration. Stem Cells International, 2016, 5756901 .

94. Dutta, P., Sager, H. B., Stengel, K. R., Naxerova, K., Courties, G., Saez, B., Silberstein, L., Heidt, T., Sebas, M., \& Sun, Y. (2015). Myocardial infarction activates CCR2 + hematopoietic stem and progenitor cells. Cell Stem Cell, 16(5), 477-487.

95. Della Gatta, P. A., Cameron-Smith, D., \& Peake, J. M. (2014). Acute resistance exercise increases the expression of chemotactic factors within skeletal muscle. European Journal of Applied Physiology, 114(10), 2157-2167.

96. Emmons, R., Niemiro, G. M., Owolabi, O., \& De Lisio, M. (2016). Acute exercise mobilizes hematopoietic stem and progenitor cells and alters the mesenchymal stromal cell secretome. Journal of Applied Physiology, 120(6), 624-632.

97. Si, Y., Tsou, C.-L., Croft, K., \& Charo, I. F. (2010). CCR2 mediates hematopoietic stem and progenitor cell trafficking to sites of inflammation in mice. The Journal of Clinical Investigation, 120(4), 1192-1203.

98. Mooren, F. C., \& Kruger, K. (2015). Apoptotic lymphocytes induce progenitor cell mobilization after exercise. Journal of Applied Physiology (Bethesda, MD: 1985), 119(2), 135-139.

99. Mars, M., Govender, S., Weston, A., Naicker, V., \& Chuturgoon, A. (1998). High intensity exercise: a cause of lymphocyte apoptosis? Biochemical and Biophysical Research Communications, 249(2), 366-370.

100. Krüger, K., Frost, S., Most, E., Volker, K., Pallauf, J., \& Mooren, F. C. (2009). Exercise affects tissue lymphocyte apoptosis via redox-sensitive and Fas-dependent signaling pathways. American Journal of Physiology. Regulatory, Integrative and Comparative Physiology, 296(5), R1518-R1527.

101. Pittenger, M. F., Mackay, A. M., Beck, S. C., Jaiswal, R. K., Douglas, R., Mosca, J. D., Moorman, M. A., Simonetti, D. W., \& Craig, S. (1999). Multilineage potential of adult human mesenchymal stem. Science, 284, 5411.

102. Deans, R. J., \& Moseley, A. B. (2000). Mesenchymal stem cells: biology and potential clinical uses. Experimental Hematology, 28(8), 875-884.

103. Uccelli, A., Moretta, L., \& Pistoia, V. (2008). Mesenchymal stem cells in health and disease. Nature Reviews. Immunology, 8(9), 726-736.

104. Shariatzadeh, M., Song, J., \& Wilson, S. L. (2019). The efficacy of different sources of mesenchymal stem cells for the treatment of knee osteoarthritis. Cell Tissue Res 378(3), 399-410.

105. Marędziak, M., Śmieszek, A., Chrząstek, K., Basinska, K., \& Marycz, K. (2015). Physical activity increases the total number of bone-marrow-derived mesenchymal stem cells, enhances their osteogenic potential, and inhibits their adipogenic properties. Stem Cells International, 2015, 379093.

Publisher's Note Springer Nature remains neutral with regard tojurisdictional claims in published maps and institutionalaffiliations. 